NASA Contractor Report 4195

\title{
A Study of the Stress \\ Wave Factor Technique \\ for Evaluation of \\ Composite Materials
}

J. C. Duke, Jr., E. G. Henneke II,

M. T. Kiernan, and P. P. Grosskopf

Virginia Polytechnic Institute and State University

Blacksburg, Virginia

Prepared for

Lewis Research Center

under Grant NAG3-172

\section{NMSA}

National Aeronautics

and Space Administration

Scientific and Technical

Information Division 


\section{PREFACE}

Retrospectively the path of progress seems exceedingly clear. Wrong turns seem all but too obvious. During the work on this program a number of previous interim reports have been written. It would appear to have been a wise decision to numbers these reports as a series. This was unfortunately not done originally. Nevertheless, hoping not to seem presumptuous the following numbering will be used subsequently:

Interim Report-I -- NASA Contractor Report 3670 "A Study of the Stress Wave Factor Technique for Characterization of Composite Materials", E. G. Henneke, II, J. C. Duke, Jr., W. W. Stinchcomb, A. Govada, and A. Lemascon (1983).

Interim Report-II -- NASA Contractor Report 174870 "A Study of the Stress Wave Factor Technique for Characterization of Composite Materials", A. K. Govada, J. C. Duke, Jr., E. G. Henneke, II, and W. W. Stinchcomb (1985).

Interim Report-III -- NASA Contractor Report 4002 "A Study of the Stress Wave Factor Technique for Characterization of Composite Materials" A. Sarrafzadeh (-Khoee), M. T. Kiernan, J. C. Duke, Jr., and E. G. Henneke, II (1986).

In addition to instituting the numbering sequence the introduction of this report is meant to serve as a state-of-the-art review of our understanding of the acoustoultrasonic method as applied to the nondestructive evaluation of advanced materials. 


\section{TABLE OF CONTENTS}

INTRODUCTION

Background $\quad 1$

Techniques for Implementation $\quad 3$

Instrumentation $\quad 5$

Data Interpretation $\quad 9$

MICROSTRUCTURAL ACOUSTICS $\quad 13$

$\begin{array}{ll}\text { Philosophy of Approach } & 13\end{array}$

$\begin{array}{ll}\text { Transverse Resonance Modes } & 13\end{array}$

AU EVALUATION OF ORGANIC COMPOSITE MATERIALS 20

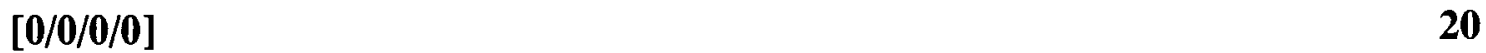

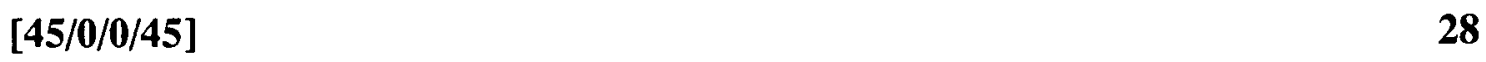

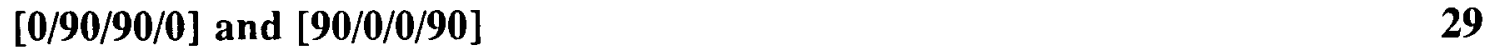

AU EVALUATION OF CERAMIC COMPOSITE MATERIALS 35

Literature Survey $\quad 35$

Correlation With UItrasonic C-scan Results $\quad 42$

LASER IN/OUT AU $\quad 48$

Laser Interferometric Detection $\quad 48$

$\begin{array}{ll}\text { Laser In } & 48\end{array}$

$\begin{array}{lc}\text { REFERENCES } & \mathbf{5 0}\end{array}$

$\begin{array}{ll}\text { APPENDIX } & \mathbf{5 2}\end{array}$ 


\section{INTRODUCTION}

\section{Background}

The original intention of Alex Vary, the originator of the acousto-ultrasonic (AU) method, was to provide a measurement procedure that would be able to quantify the integrated effect of the globally distributed damage characteristic of fiber reinforced composite materials. 1 The original evaluation procedure provided a "stress wave factor" that correlated closely with several material performance parameters. The original procedure involved introducing a mechanical excitation into a sample by means of a piezoelectric ultrasonic transducer and detecting the resulting disturbance at another point a short distance $(1 \mathrm{in.}, 3 \mathrm{~cm})$ away on the same surface using an acoustic emission sensor. This received voltage signal was directed to a counter that counted the oscillations above a selected threshold voltage per selected time interval, while the excitation occurred repetitively. This quantification procedure was examined in detail by Henneke et. al. in NASA CR 3670 (Interim Report-I).

Since the introduction of this evaluation procedure it has been considered for application to a variety of situations, including:

- advanced composites

- bonding of hybrid structures

- adhesive bond strength

- wood products

- wire rope

Although the original approach had as its objective materials characterization the procedure has been adapted for flaw detection in some instances. The activity of the research program reported here has focused primarily on the development of a fundamental understanding and the advancement of fundamental applications that utilize the AU method for characterization of materials for which detection, location and identification of imperfection can not at present be analyzed with satisfactory mechanical performance prediction models. This is not to say that the use of AU for flaw detection is unimportant, but rather to point out that the work reported here has not been directed at optimizing this capability; the opposite may at time be the case.

Now as with all nondestructive evaluation method development it is essential to establish as clearly as possible the nature of the material attribute that is the subject of the evaluation. Generally two situations need be considered: On the one hand is the 
question "What size must the maximally severe imperfection be before detection is possible?", while on the other we wonder "How severe must the globally distributed damaged condition become before detection is possible?". If accept/reject criteria are available the identification and engineering development of the NDE method may be carried out. This is not the case advanced composite materials and this has made this approach more challenging in that the size of the maximally severe imperfection, e.g. a hole, and the severity of globally distributed damage are easily within the detection capabilities of NDE. Therefore the objective - predicting the stiffness and durability of a advanced material component - is being pursued from at least two directions. One in which modelling is directed at understanding how damage will degrade the mechanical performance while the other seeks to relate the nondestructively evaluated mechanical performance of the degraded material/component, using the AU method or other nondestructive materials characterization methods, to the anticipated inservice performance.

Physical Basis- Philosophically the AU approach endeavors to examine the mechanical performance of a material using a mechanical excitation that propagates in a direction similar to that of inservice loading. Since the mechanical excitation is dynamic its interaction with the material and any damage present is expected to be similar to the interaction that would occur with stress released during additional damage initiation or development. The magnitude of the mechanical excitation associated with the AU method is globally quite small and generally is assumed to affect only linear elastic reactions. The actual effect in damaged regions is unknown. Whether it is reasonable to anticipate a correlation between performance at this level of mechanical loading and that present at failure of the component is a continuing matter of consideration in this program.

Wave Propagation- With the introduction of a short duration mechanical excitation into a material consideration of the nature of the propagation of the energy associated with the excitation away from the point of excitation must certainly involve the discussion of wave propagation. The details of such a discussion depend on the assumed, or known description of the excitation, the properties of the material/structure, and the boundary conditions. Efforts to explain aspects of the behavior observed using the AU procedure by Williams et. al. ${ }^{2}$ and $\mathrm{Kautz}^{3}$ have utilized ray analysis, while workers at VPISU ${ }^{4}$ have considered plate modes; more regarding recent work is included later in this report. 
In 1987 the Acoustical Society of America formed a committee on "Structural Acoustics and Vibrations" that has focus consideration on the macroscopic aspects of acoustic pressure disturbances associated with structures. The authors see significant similarities and have coined the label "Microstructural Acoustics" to generally describe work directed at explaining the nature of the wave propagation and energy partitioning in composite materials where the fiber architecture/matrix combination constitute the structure.

\section{Techniques for Implementation}

The AU method is very sensitive to the material condition and as such may appear to provide results that are difficult to reproduce if care is not taken. Figure 1 is a photograph of a full field moire interferometric pattern associated with the nonuniform part of the displacement that occurs in a graphite epoxy laminate that has been loaded in uniform uniaxial tension. The nonuniformities must be the result of imperfections in the microstructural arrangement of fibers and matrix, and laminae.

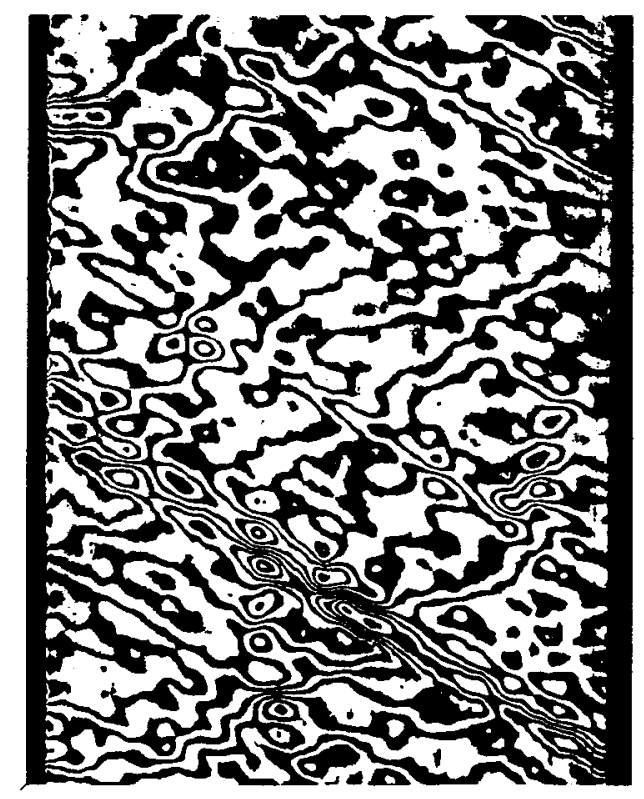

Fig. 1. Photograph of a moire interferometric fringe pattern that provides a full-field map of the in-plane axial displacement. The pitch of the reference grating has been adjusted to subtract out the uniform axial tensile elongation leaving only the nonuniform portion. (Courtesy of the VPISU Photomechanics Laboratory; D. Post, Director) 
Such nonuniformities will influence AU measurements and can be the cause of the lack of reproducibility that may be observed. Therefore extreme care must be taken when positioning transducers for AU measurement. If contact transducers are utilized, in addition to placement, the orientation of the transducer elements as well as the amount and distribution of the impedance matching couplant must be repeated to achieve reproducibility. If composite materials containing surface breaking damage are being considered noncontact or dry coupled transducers are recommended. Wet coupled transducers may be used successfully if the dwell time of the couplant is short.

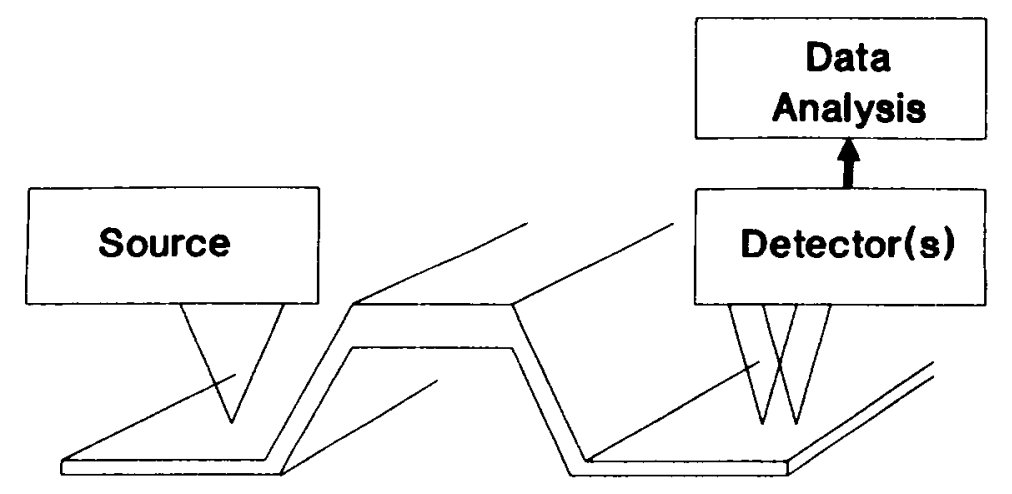

\begin{tabular}{lll} 
Source & Detector(s) & Data Analysis \\
\hline - Fracture & - Contact & - Digital Data Acquistion \\
- Piezoelectric & Piezoelectric & Data Filtering \\
- Impact & Phase Insensitive & Data Averaging \\
Solid Object & - NonContact & - Spectrum Analysis \\
Fluid & Laser & Frequency Filtering \\
- Laaser & EMAT & Transfer Function \\
- EMAT & Capacitor & Spectrum Moments / SWF
\end{tabular}

Fig. 2. Generalized schematic of the Acousto-Ultrasonic (AU) method

Figure 2 is a generalized schematic of the AU measurement arrangement. Depending on the material system, the measurement objective, and the application constraints numerous possible combinations of source, detector(s) and data analysis are possible. 


\section{Instrumentation}

Transducers - Figures 3-6 are examples of several source and detector combinations; both voltage versus time and amplitude spectrum plots are provided. A Panametrics Model 5052UA pulser receiver and, where required, a Panametrics preamplifier were used along with a General Research PCDAS acquisition board installed in an ARC Turbo XT to obtain the results. Figure $3 \mathrm{a}$ and $\mathrm{b}$ are results from using a $5 \mathrm{MHz}, 0.5$ in. diameter, (Panametrics V109) ultrasonic transducers as both source and detector; the damping setting was $200 \Omega$, the energy setting was $110 \mu \mathrm{J}$ and the gain was $46 \mathrm{~dB}$. Figure $4 \mathrm{a}$ and $\mathrm{b}$ are results from using a 0.25 in. diameter, $5 \mathrm{Mhz}$, (Ultran KD25-5) dry coupled transducer as a detector and the same source as in Fig. 3; the gain was increased to $66 \mathrm{~dB}$. Figure $5 \mathrm{a}$ and $\mathrm{b}$ are results from using a pulsed laser excitation (Kigre MK-480 YAG Laser System) as the source and a $100 \mathrm{kHz}$ Panametrics AE sensor as the detector; the preamplifier was used to provide $40 \mathrm{~dB}$ gain. The pulsed excitation occurred on a 1" $x 6$ " Gr/Ep specimen 4 inches from the detector location. Figure $6 \mathrm{a}$ and $\mathrm{b}$ are results from using the same source as that used in Fig. 3 and a conical "Proctor" transducer as a detector.
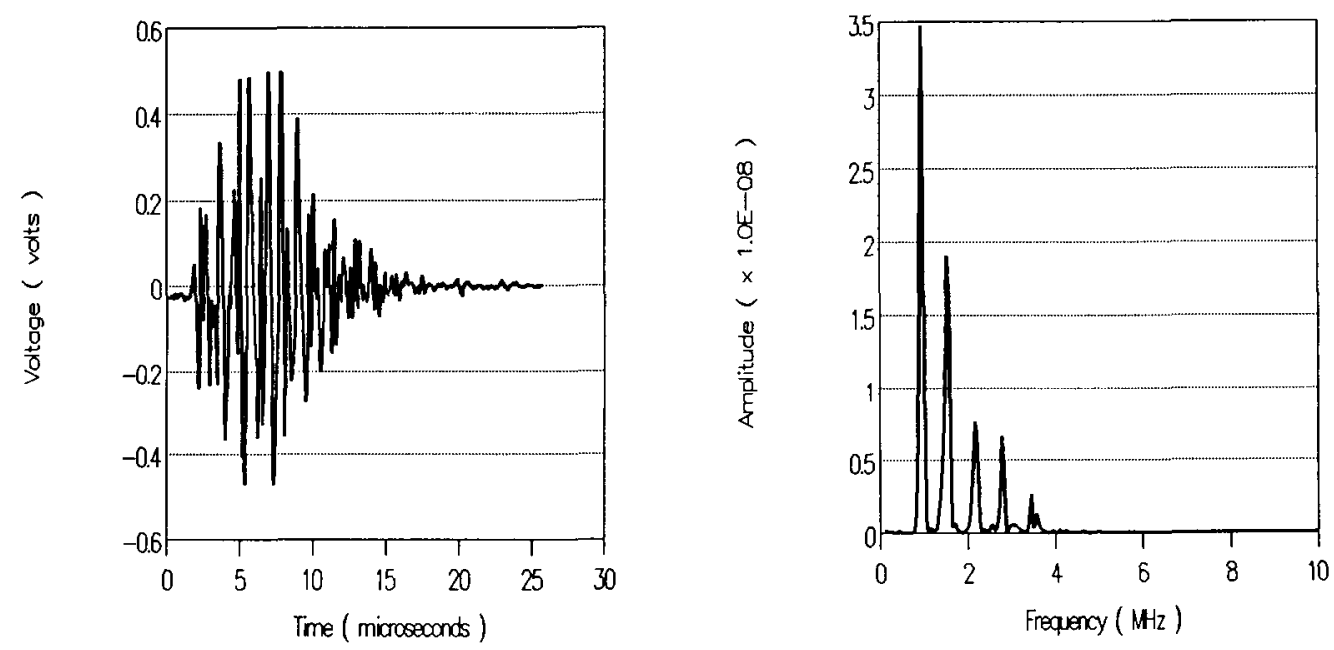

Fig. 3. a) Voltage versus time and b) amplitude spectrum for the signal detected using a $0.5 \mathrm{in}$. diameter, $5 \mathrm{MHz}$ transducer as a source and another as the detector. 

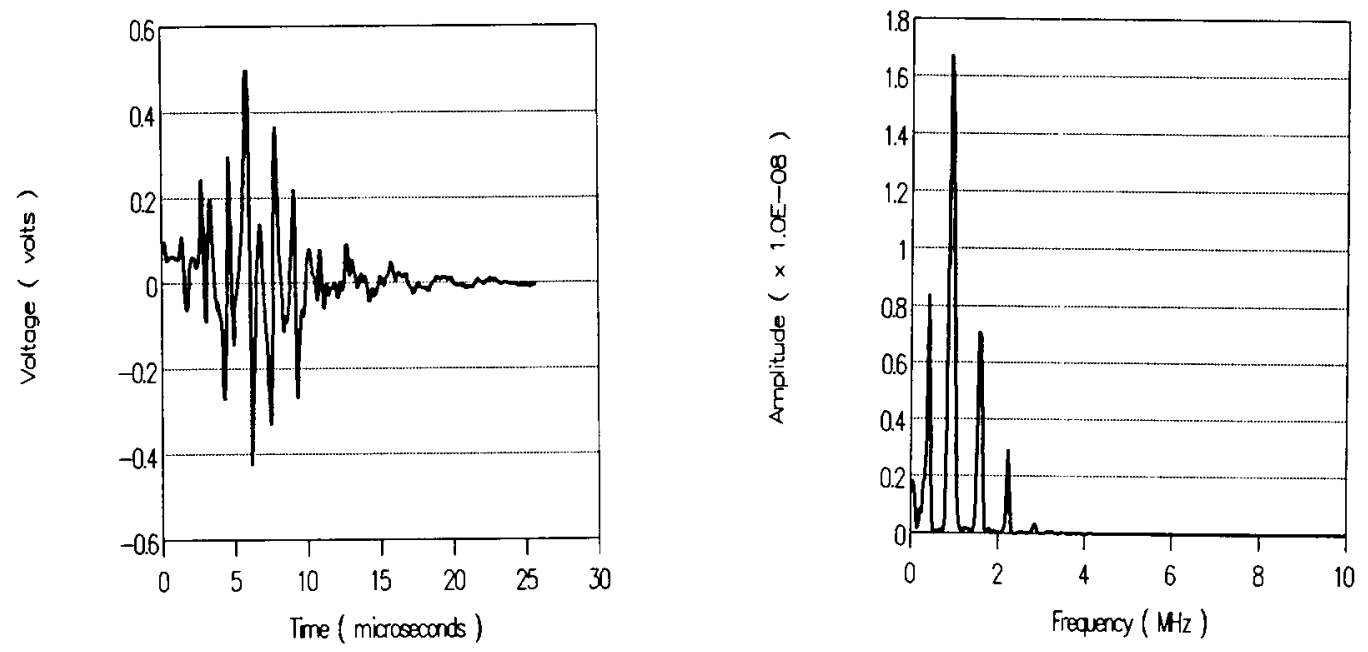

Fig. 4. a) Voltage versus time and b) amplitude spectrum for the signal detected using a $0.5 \mathrm{in}$. diameter, $5 \mathrm{MHz}$ transducer as a source and a $0.25 \mathrm{in}$. diameter $5 \mathrm{MHz}$ dry coupled transducer as the detector.
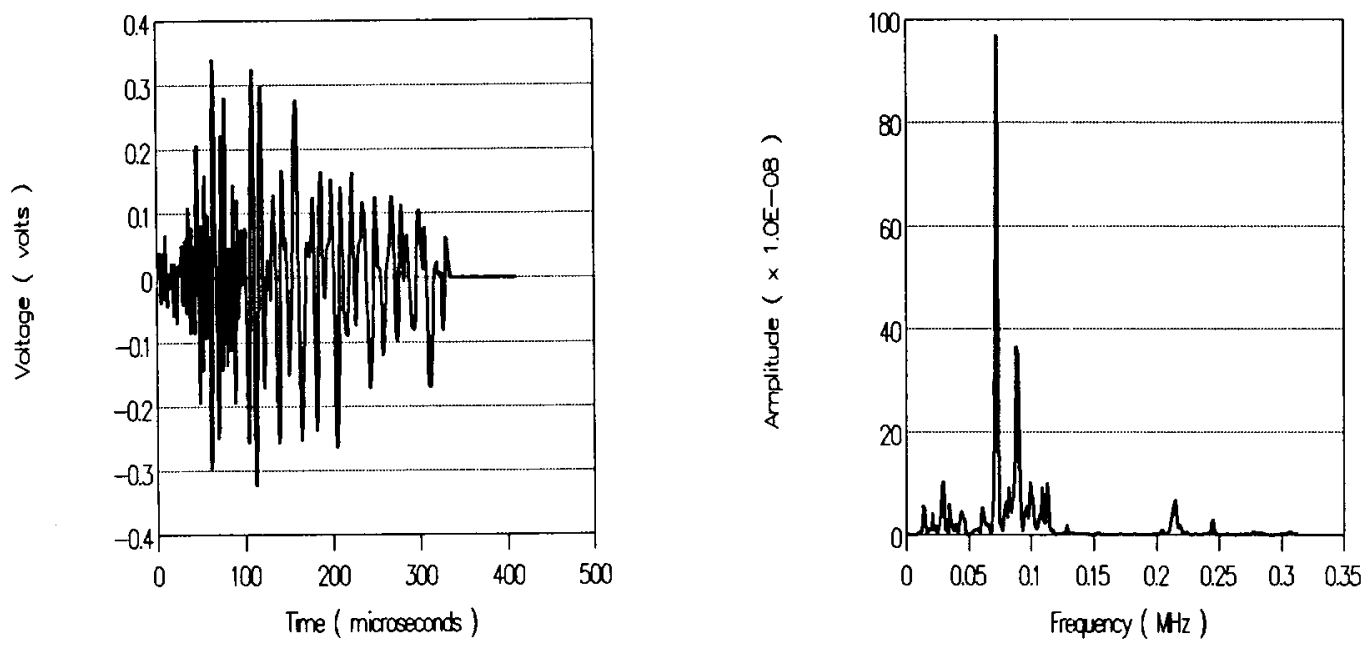

Fig. 5. a) Voltage versus time and b) amplitude spectrum for the signal obtained using a pulsed laser source and a 0.5 in diameter, $100 \mathrm{kHz}$ AE transducer as the detector. 

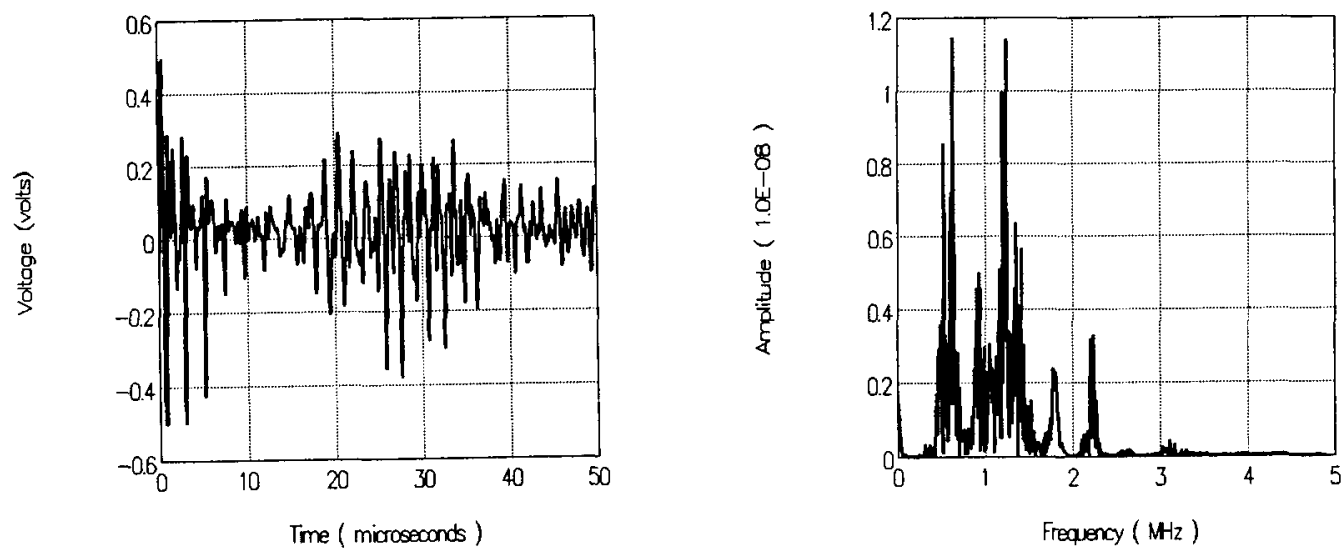

Fig. 6. a) Voltage versus time and b) amplitude spectrum for the signal obtained using a 0.5 in diameter, $5 \mathrm{MHz}$ transducer as the source and a conical piezoelectric, "Proctor" transducer as the detector.

Previous work by Rebello and Duke ${ }^{5}$ reported results obtained using a pencil lead break source and a capacitance sensor as a detector. For applications where the component is of conducting material electromagnetic acoustic transducers are worthy of consideration 6 . In addition it is worth noting as well that multiple transducer AE monitoring arrangements are capable of being used for AU measurement without significant modification. In fact many systems utilize one or more of the sensors as sources for transducer/system calibration. Such a procedure is reasonable for AE monitoring prior to the occurrence of damage, e.g. before beginning of service or proof testing, or with components that generally fail due to propagation of localized self-similar damage development, i.e. cracks. With components that sustain global damage changes observed upon "calibration" during service or testing may be the result of changes in the condition of the material of the component. Therefore in addition to being able to detect the occurrence and propagation of damage through conventional AE monitoring the "calibration" procedure can be used to perform AU measurements that would indicate the integrated effect of the sources of the AE. One might imagine using $\mathrm{AE}$ source/zone location to identify areas for which $\mathrm{AU}$ measurement would then be accomplished by using the appropriate $\mathrm{AE}$ transducers as sources with others acting as AU detectors. 
Data Acquisition/Analysis- The approach to acquiring and analyzing the AU data for engineering application or research development may differ. Generally for research the emphasis is placed on flexibility while with the engineering application speed of analysis is at a premium. In the Materials Response Laboratory at VPISU the overriding objective is to understand the mechanical performance of advanced material systems, so consequently it is desirable to consider the observed AU response from a variety of perspectives. However, once the analysis procedure is selected and refined, by stripping flexibility, considerable economy as regards time to analyze the $\mathrm{AU}$ performance is possible.

The system used for most of the results presented in this report includes a PC based digital data acquisition board, either the General Research 1 channel, $20 \mathrm{MHz}$ real-time ( $160 \mathrm{MHz}$ equivalent time) sampling, 4096 point record length PCDAS, or the Sonotek 2 channel, $25 \mathrm{MHz}$ real-time (200 MHz equivalent time) sampling, $64 \mathrm{k}$ record length STR*825, and analysis software developed in-house. It should be pointed out that analog data analysis is preferable in some applications, but digital data storage and analysis is significantly more convenient during the development phase.

The analysis software developed has been described in some detail earlier by Kiernan and Duke 7 . Emphasis has been placed on considering the spectral domain results in an effort to identify various modes of energy propagation. The component geometry, the matrix/fiber architecture of the material and the damage condition are all seen as contributing factors to how the energy is partitioned into various modes of propagation. By considering the nature of the source, the boundary conditions and the material properties progress is being made in unfolding the complicated collection of modes participating. Identifying the modes is expected to lead to a more complete understanding of why the AU behavior correlates with mechanical performance. In the meantime as this understanding increases the exploration of the correlation with various types of damage that occurs in advanced composites continues. To simplify the chore of comparing the AU response from point to point, or from material to material the use of a method developed to quantify random noise 8 was suggested. ${ }^{9}$ The purpose was to quantify the nature of the AU signal by means of a small set of parameters or stress wave factors making comparison much easier than that required to compare the entire temporal or spectral domain information. This approach defines several quantities in terms of spectral moments that have physical meaning when applied to "stationary" noise signals. Since noise signals are random these measures 
are essentially statistical. Care must be exercised however in translating the original interpretation over to the AU signals.

$$
M_{n}=\int_{0}^{f_{\max }} f^{n_{S}(f) d f}
$$

$\mathrm{M}_{\mathrm{o}}$ is the zeroth moment of the Power Spectral Density Distribution and is proportional to the energy of the signal. $\mathrm{M}_{1} / \mathrm{M}_{0}$ is the centroid frequency of the power spectrum.

The observation of favored energy bands in the spectral domain of AU signals has motivated a specialization of this method. 10

$$
A 1\left(f_{a}, f_{b}\right)=\int_{f_{a}}^{f_{b}} S(f) d f \quad A 2=M_{1} / M_{\circ}
$$

( $a$ and $b$ indicate upper and lower limits of the frequency band of interest)

Note: A's are used to denote versions of Rice's original measures that have been specialized for purposes of AU evaluation.

By evaluating the area under a portion of the power spectral density distribution of the AU signal it is possible to estimate the energy associated with particular modes or combinations of modes of energy propagation. Tracking the manner in which this measure changes provides greater sensitivity to stiffness and durability degrading damage, than other AU measures considered.

The software provides other means of comparing AU response (signals) as well as allowing for statistical evaluation of a set of AU response measurements in order to determine a single representative value. ${ }^{11}$

\section{Data Interpretation}

Consider a thin graphite fiber reinforced epoxy laminate where a $5 \mathrm{Mhz}, 0.5 \mathrm{in}$. diameter transducer is used as a source and a $5 \mathrm{MHz}, 0.5 \mathrm{in}$. diameter transducer placed one inch away on the same surface where the line passing through the transducer centers is parallel to a fiber direction. Figure 7 displays the variation of A1, for such an experimental arrangement, as a function of azimuthal angle. The center 
position of the source transducer is maintained in the same location. The transducer source/detection tandem is however removed and replaced at the various angles for which measurements are made. Insets show the spectra for the $0^{\circ}, 45^{\circ}$ and $90^{\circ}$ orientations. When considering the spectrum of the signals detected in this manner two frequency "peaks", or bands appear to contain a significant amount of the energy. The frequencies $\approx 1 \mathrm{MHz}$ and $\approx 3.2 \mathrm{MHz}$ are significantly less than the center frequency of the transducers used. The first peak is consistent with the frequency of the fundamental extensional (symmetric) plate mode and the second with the flexural (antisymmetric) mode; see section on "Microstructural Acoustics" and the Appendix for more details.

As a simple rule of thumb the energy from the mechanical disturbance tends to travel most readily in the fiber directions. Figure 8 shows the variation of the energy as represented by $\mathrm{A} 1$ as a function of azimuthal angle for a [0/90]s laminate. A1 for the $0^{\circ}$ direction is 4 times that for the $45^{\circ}$ direction while that for the $90^{\circ}$ direction is 3 times. This energy dissipation is of course dynamic with the energy flux in fibers and matrix material and from ply to ply being influenced by the intimacy of the mechanical bonding that exists between these various entities.

The software mentioned earlier ${ }^{7}$ is able to compare to signals either from different locations, different specimens, or from the same specimen at different points during the course of its life. This aspect has not yet been explored in a substantive way so consequently nomenclature appropriate for the description of this data has not been developed. 


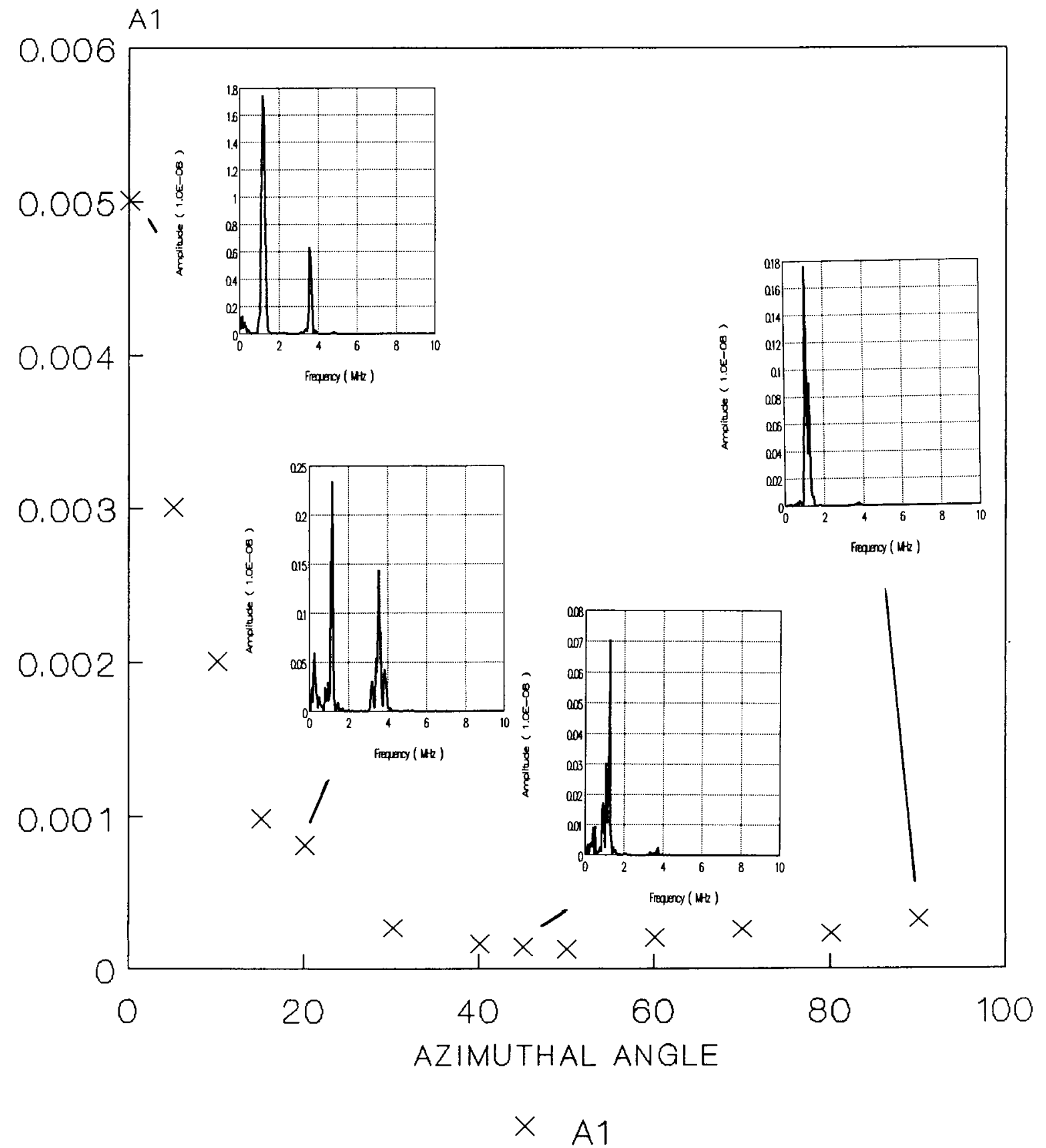

Fig. 7. A1 versus azimuthal angle for a $[0 / 0 / 0 / 0] \mathrm{s} \mathrm{Gr} / \mathrm{Ep}$ laminate. The measurements were made by rotating a pair of 0.5 in. diameter, $5 \mathrm{MHz}$ transducers about an axis through the center of the location of the source transducer. (Actually both of the transducers are completely removed and then placed into the appropriate position each time a measurement is made.) 


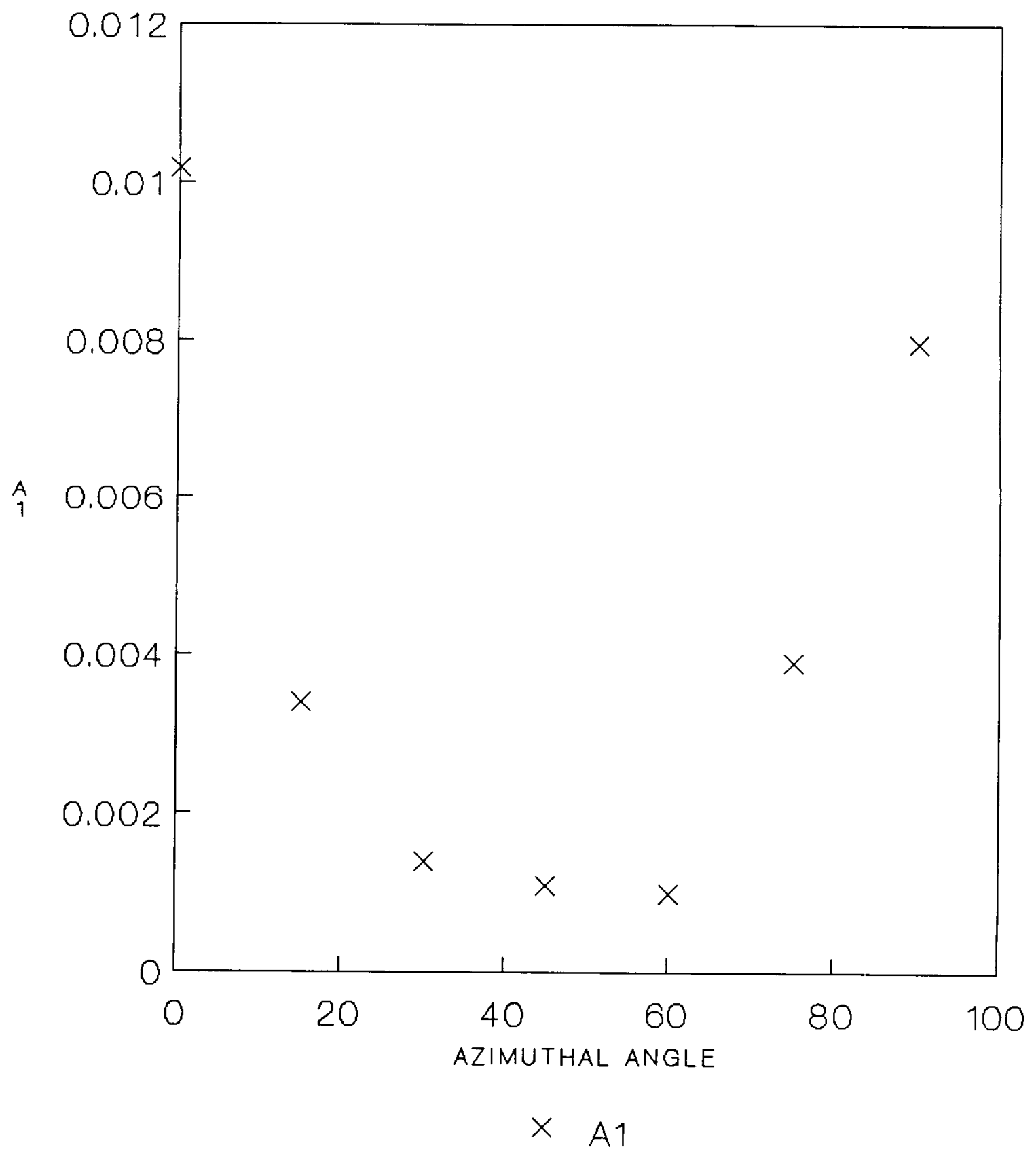

Fig. 8. A1 versus azimuthal angle for a [0/90]s $\mathrm{Gr} / \mathrm{Ep}$ laminate. 


\section{MICROSTRUCTURAL ACOUSTICS}

\section{Philosophy of Approach}

Understanding the nature of energy propagation away from the source of a mechanical disturbance in a fiber reinforced composite material is complicated by more than just the orthotropic or transversely isotropic material symmetry. The material is anisotropic and inhomogeneous by design on the scale of the fiber, laminae, and possibly the component level and also by lack of precise processing. The distribution and orientation of fibers is usually not ideal, and material and processing variations lead to uncertainty in mechanical properties for analysis of AU behavior. To systematically approach the investigation of laminated composite materials a decision as to how to deal with coupled influence of geometry, lamina properties, and laminae interaction must be made.

\section{Transverse Resonance Modes}

Initially efforts in this research program have been restricted to situations in which plate mode propagation is readily possible with sources suggested earlier. Preliminary to actually considering the case of the fiber reinforced composite plate the case of a "monolithic isotropic plate" was examined.

The classical treatment of plate waves by Rayleigh and later by Lamb have considered the motion of thin isotropic, homogeneous plates. With AU method the short wavelengths associated with the high frequencies necessitate utilizing a 3-D elasticity analysis. A full development for the case of an isotropic plate, as well as the preliminary development appropriate for an anisotropic plate is presented in the Appendix. For means of comparison and to provide a measure of confidence in the explanations being put forth the special case of the simple thickness, transverse resonance, modes of a $6061-\mathrm{T} 6$ aluminum, Table 1 , and an AS-4Gr/Pr $288[0]_{8}$ graphite fiber reinforced epoxy plate, Table 2 , is presented here. 
TABLE 1: Description of 6061-T6 Aluminum Plate

$\mathrm{E}=10 \times 10^{6} \mathrm{psi} \quad \mathrm{G}=3.75 \times 10^{6} \mathrm{psi} \quad \rho=2.536 \times 10^{-4}\left(\mathrm{lb}-\mathrm{s}^{2}\right) / \mathrm{in}^{4}$

Plate thickness $\mathrm{t}=0.0625$ in.

$\mathrm{C}_{22}=\mathrm{C}_{33}=(1-\nu) \mathrm{E} /(1+\nu)(1-2 \nu)=15 \times 10^{6} \mathrm{psi}$

$\mathrm{C}_{55}=\mathrm{E} /[2(1+\nu)]=\mathrm{G}$

\section{TABLE 2: Description of AS-4Gr/PR $288[0]_{8}$ Graphite/Epoxy Plate}

$E_{11}=18.3 \times 10^{6}$ psi $\quad E_{22}=1.3 \times 10^{6} p s i \quad G_{12}=0.66 \times 10^{6} p s i$

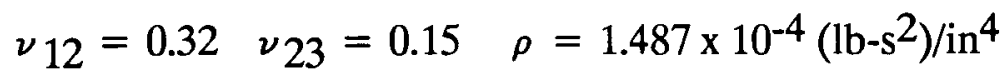

Plate thickness $t=0.088$ in.

$\mathrm{C}_{33}=\left(1-\nu_{12}{ }^{2} \mathrm{E}_{22} / \mathrm{E}_{11}\right) \mathrm{E}_{22} / \mathrm{V}=1.34 \times 10^{6} \mathrm{psi}$

$\mathrm{V}=\left[\left(1+\nu_{23}\right)\left(1-\nu 23-2 \nu_{12}{ }^{2} \mathrm{E}_{22} / \mathrm{E}_{11}\right)\right]$

$\mathrm{C}_{55}=\mathrm{G}_{12}$

The resonant frequencies for the simple thickness modes may be obtained by setting $\Phi=0$ in eqns. A10 - A32. The following resonant, or "cutoff" frequencies result:

$$
\omega=\mathrm{m} \pi \mathrm{v}_{\mathrm{p}} / 2 \mathrm{~b} \quad \omega=\mathrm{n} \pi \mathrm{v}_{\mathrm{S}} / 2 \mathrm{~b}
$$

(2) symmetric case -

$$
\begin{array}{lll}
\mathrm{u}_{1}=0 & \mathrm{u}_{2}=\mathrm{B}^{\prime} \sin \left(\mathrm{m} \pi \mathrm{x}_{2} / 2 \mathrm{~b}\right) & \mathrm{m}=1,3,5, \ldots \\
\mathrm{u}_{2}=0 & \mathrm{u}_{1}=\mathrm{C}^{\prime} \cos \left(\mathrm{n} \pi \mathrm{x}_{2} / 2 \mathrm{~b}\right) & \mathrm{n}=2,4,6, \ldots
\end{array}
$$


(3) antisymmetric case -

$$
\begin{array}{lll}
\mathrm{u}_{2}=0 & \mathrm{u}_{1}=\mathrm{D}^{\prime} \sin \left(\mathrm{n} \pi \mathrm{x}_{2} / 2 \mathrm{~b}\right) & \mathrm{n}=1,3,5, \ldots \\
\mathrm{u}_{1}=0 & \mathrm{u}_{2}=\mathrm{A}^{\prime} \cos \left(\mathrm{m} \pi \mathrm{x}_{2} / 2 \mathrm{~b}\right) & \mathrm{m}=2,4,6, \ldots
\end{array}
$$

$$
\mathrm{v}_{\mathrm{p}}=\left(\mathrm{C}_{22} / \rho\right)^{.5} \quad \mathrm{v}_{\mathrm{s}}=\left(\mathrm{C}_{44} / \rho\right)^{.5}
$$

TABLE 3: Frequencies and Displacements for Transverse Resonance Modes

Mode Number

0

1

2

3

4
Symmetric

0

$$
\begin{gathered}
\mathrm{f}=\mathrm{v}_{\mathrm{p}} / 4 \mathrm{~b} \\
\mathrm{u}_{1}=0 \\
\mathrm{u}_{2}=\mathrm{B}^{\mathrm{c}}
\end{gathered}
$$$$
\mathrm{f}=\mathrm{v}_{\mathrm{S}} / 2 \mathrm{~b}
$$$$
\mathrm{u}_{1}=\mathrm{C}^{\mathrm{s}}
$$$$
\mathrm{u}_{2}=0
$$$$
\mathrm{f}=3 \mathrm{v} \mathrm{p} / 4 \mathrm{~b}
$$$$
\mathrm{u}_{1}=0
$$$$
\mathrm{u}_{2}=-\mathrm{B}^{\mathrm{c}}
$$$$
\mathrm{f}=\mathrm{v}_{\mathrm{S}} / \mathrm{b}
$$$$
\mathrm{u}_{1}=-\mathrm{C}^{\mathrm{c}}
$$$$
\mathrm{u}_{2}=0
$$

Antisymmetric

$$
0
$$

$$
\begin{aligned}
& \mathrm{f}=\mathrm{v}_{\mathrm{S}} / 4 \mathrm{~b} \\
& \mathrm{u}_{1}=\mathrm{D}^{\mathrm{c}} \\
& \mathrm{u}_{2}=0 \\
& \mathrm{f}=\mathrm{v}_{\mathrm{p}} / 2 \mathrm{~b} \\
& \mathrm{u}_{1}=0 \\
& \mathrm{u}_{2}=-\mathrm{A}^{\prime} \\
& \mathrm{f}=3 \mathrm{v}_{\mathbf{S}} / 4 \mathrm{~b} \\
& \mathrm{u}_{1}=-\mathrm{D}^{\prime} \\
& \mathrm{u}_{2}=0
\end{aligned}
$$

$$
\begin{array}{r}
f=v_{p} / b \\
u_{1}=0 \\
u_{2}=A^{\prime}
\end{array}
$$

The first symmetric, the second antisymmetric, and the third symmetric modes have non-zero displacements in the $\mathrm{x}_{2}$ direction. However, due to the Poisson effect the modes with non-zero $\mathrm{u}_{1}$ displacements may also conceivably give rise to a disturbance in the $\mathrm{x}_{2}$ direction. 
Table 4 provides the numerical values for the aluminum plate described by Table 1, while Table 5 provides the numerical values for the graphite/epoxy plate described by Table 2. The Goodier-Bishop wave mention in the Appendix has a frequency, $\mathrm{f}_{\mathrm{GB}}=2.5 \mathrm{MHz}$

Figures 9 and 10 are amplitude spectra of signals obtained from the aluminum and graphite/epoxy plates respectively. In both cases a $5 \mathrm{Mhz}, 0.5 \mathrm{in}$. diameter transducer was used as a source and detector. The signal was sampled at a rate of $20 \mathrm{MHz}$ and a fast Fourier transform of the first 512 data points provided the displayed spectra. The frequencies corresponding to the various peaks have been labelled. Within the bounds of experimental accuracy a clear correspondence may be seen for both cases.

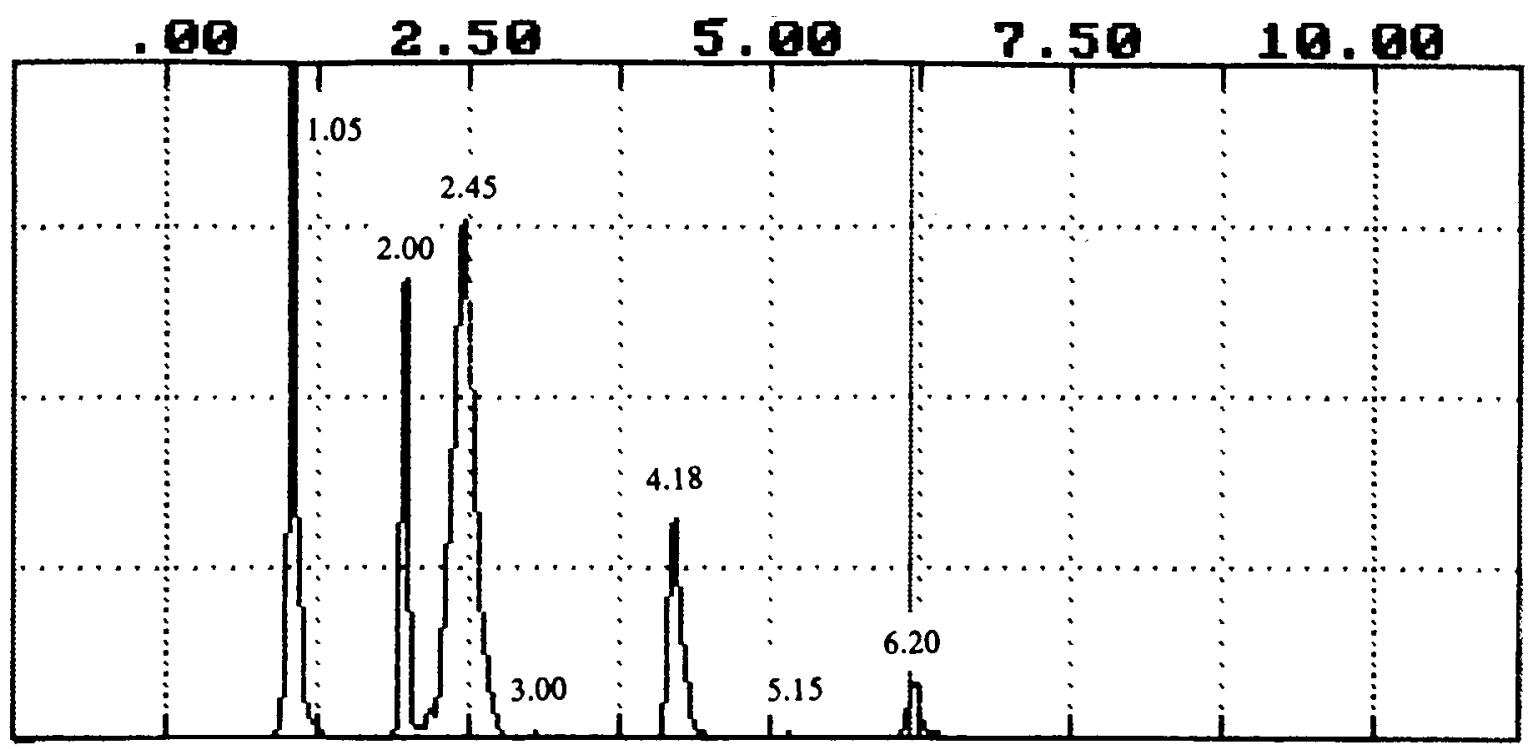

Fig. 9. The amplitude spectrum obtained using a 0.5 in. diameter, $5 \mathrm{MHz}$ transducer as a source and another similar transducer located a center-to-center distance apart of 1 inch on a 6061-T6 aluminum plate of thickness $0.0625 \mathrm{in}$. 
TABLE 4: Cutoff Frequencies for Aluminum Plate

6061-T6 (0.0625 inches thick)

\begin{tabular}{|c|c|c|}
\hline $\begin{array}{c}\text { MODE } \\
\text { NUMBER }\end{array}$ & $\begin{array}{l}\text { SYMMETRIC } \\
\text { FREQUENCY } \\
\text { (MHZ) }\end{array}$ & $\begin{array}{c}\text { ANTISYMMETRIC } \\
\text { FREQUENCY } \\
(\mathrm{MHz})\end{array}$ \\
\hline 0 & 0.0 & 0.0 \\
\hline 1 & 1.95 & .97 \\
\hline 2 & 1.95 & 3.9 \\
\hline 3 & 5.9 & 2.9 \\
\hline 4 & 3.9 & 7.8 \\
\hline 5 & 9.8 & 4.8 \\
\hline
\end{tabular}




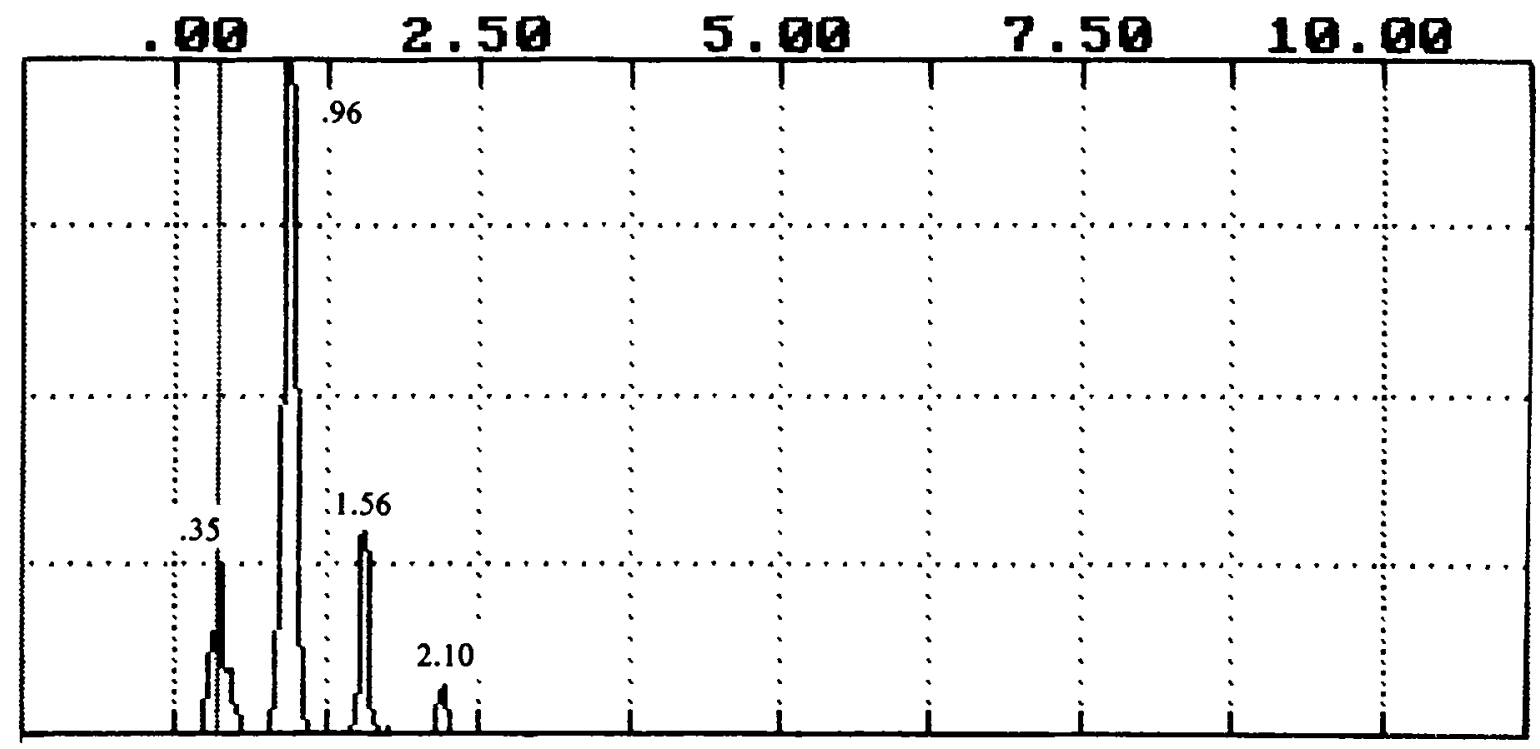

Fig. 10. The amplitude spectrum obtained using a 0.5 in. diameter, $5 \mathrm{MHz}$ transducer as a source and another similar transducer located a center-to-center distance apart of 1 inch on a unidirectional graphite fiber reinforced plate of thickness $0.088 \mathrm{in}$. 
TABLE 5: Cutoff Frequencies for Gr/Ep Plate

(AS-4 Gr/Pr 288) $[0]_{8}$ Plate

\begin{tabular}{|c|c|c|}
\hline $\begin{array}{c}\text { MODE } \\
\text { NUMBER }\end{array}$ & $\begin{array}{l}\text { SYMMETRIC } \\
\text { FREQUENCY } \\
(M H Z)\end{array}$ & $\begin{array}{l}\text { ANTISYMMETRIC } \\
\text { FREQUENCY } \\
\text { (MHz) }\end{array}$ \\
\hline 0 & 0.0 & 0.0 \\
\hline 1 & .50 & .33 \\
\hline 2 & .66 & 1.0 \\
\hline 3 & 1.5 & .99 \\
\hline 4 & 1.32 & 2.0 \\
\hline 5 & 2.5 & 1.65 \\
\hline
\end{tabular}




\section{AU EVALUATION OF ORGANIC COMPOSITE MATERIALS}

In turning attention to the fiber reinforced laminates it was decided to consider as the fundamental element, or "critical element", after the terminology of the structural analyst, a unidirectionally oriented fiber layer. The layer at times is composed of more than one ply and the orientation of the fibers in the fundamental element is considered the $0^{\circ}$ direction. The behavior of the fundamental element alone and under various forms of constraint was deemed to provide a systematic means of fully assessing the AU and correspondingly the mechanical performance of the composite material. It should be noted that the means of constraining the fundamental element are not arbitrary but are limited to those situations that may be developed experimentally.

In addition to varying the nature of the constraint of the fundamental element through the use of various stacking sequences additional conditions that result from constraint degradation due to mechanically induced damage were considered. These included matrix cracking caused by cyclic loading, damage due to impact, cracking and impact damage combined, and simulated delamination.

$[0 / 0 / 0 / 0]$

The first situation considered may for consistence be considered the case where the two ply $0^{\circ}$ fundamental element is constrained by two $0^{\circ}$ plies. Figure 11 is a plot of the modulus $E_{X}$ and $A 1$ as a function of azimuthal angle; the behavior is very similar. Figure 12 is a plot of the first element of the transformed reduced stiffness matrix, $\mathrm{Q}_{11}$, and $\mathrm{A} 1(3.2,3.4)$ as a function of azimuthal angle; $\mathrm{A} 1(3.2,3.4)$ drops off more rapidly between 20 and 30 degrees than does $Q_{11}$. Figure 13 is a plot of $v_{12}$ and A2, the centroid frequency, as a function of azimuthal angle; $\nu 12$ drops off more sharply between 40 and 80 degrees that does A2. Figure 14 is a plot of the coefficient of mutual influence and $\mathrm{A} 2$ as a function of azimuthal angle.

The AU response before and after central impact of a 3 in. $x 6$ in. plate was measured, Fig. 15. The impact ( $1.75 \mathrm{ft}-\mathrm{lb}, 2.37$ joules) was caused by a steel sphere approximately $1 \mathrm{in}$. in diameter dropped onto the specimen and captured upon the first rebound; the plate was clamped along the narrow edges, Fig. 16. Damage due to impact in this unidirectional laminate was splitting. 


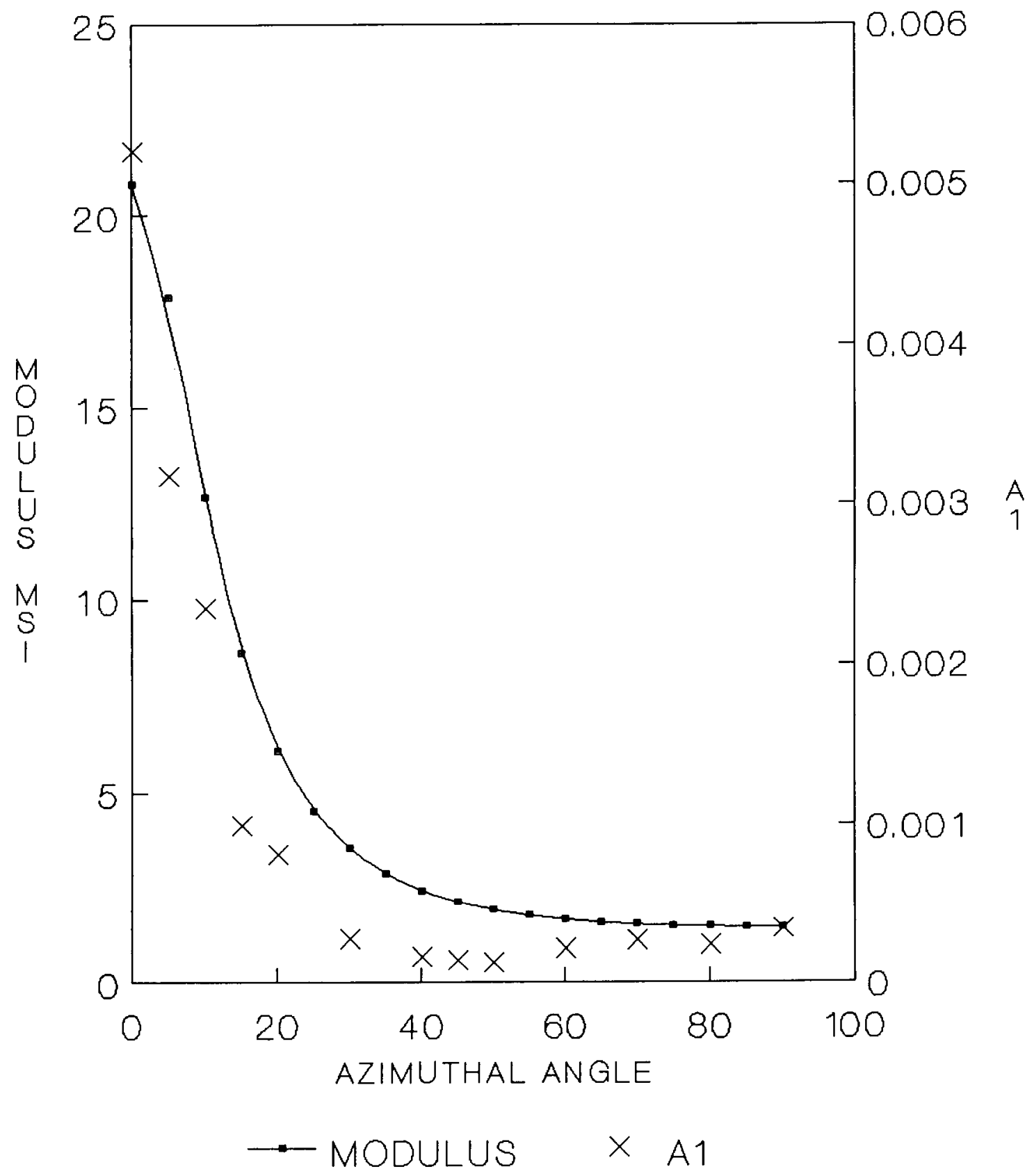

Fig. 11. Modulus, $\mathrm{E}_{\mathrm{X}}$, and $\mathrm{A} 1$ versus azimuthal angle for a thin unidirectional graphite fiber reinforced epoxy laminated plate. 


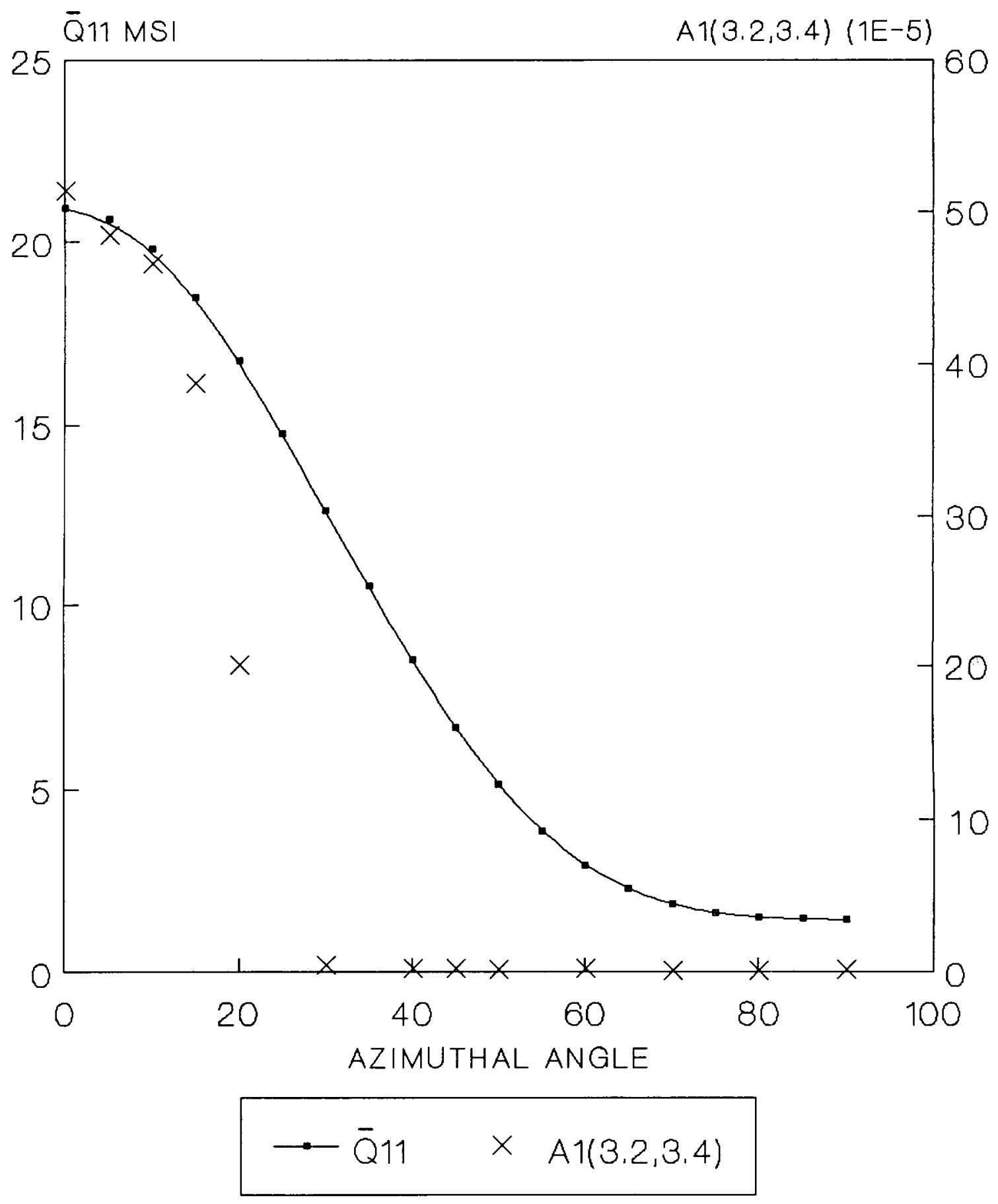

Fig. 12. $\bar{Q}_{11}$ and $\mathrm{A} 1(3.2,3.4)$ versus azimuthal angle for a thin unidirectional graphite fiber reinforced epoxy laminated plate. 


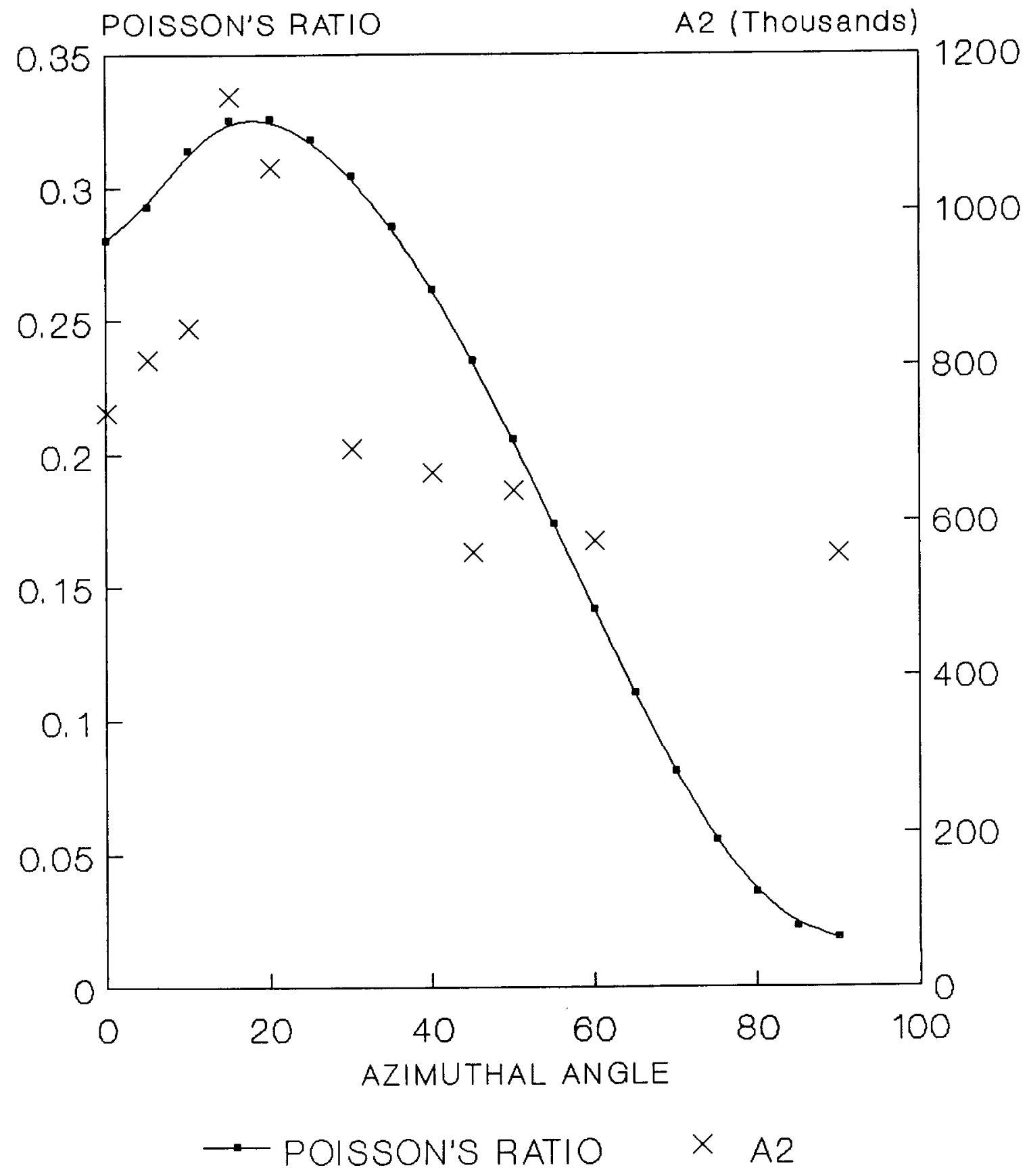

Fig. 13. Poisson Ratio, $\nu_{12}$, and A2 versus azimuthal angle for a thin unidirectional graphite fiber reinforced epoxy laminated plate. 


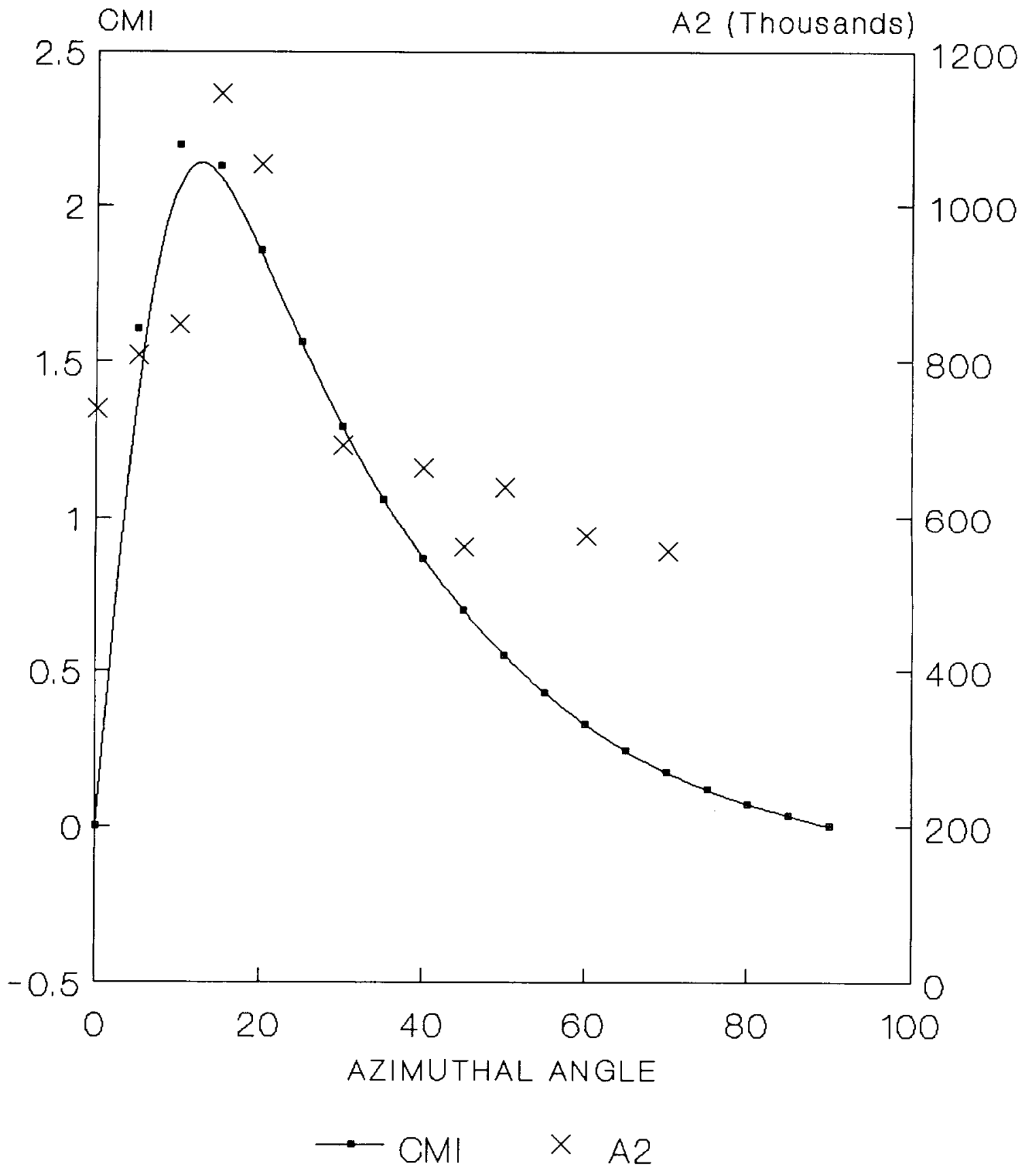

Fig. 14. Coefficient of mutual influence (CMI), $\eta_{x y, x}$, and A2 versus azimuthal angle for a thin unidirectional graphite fiber reinforced epoxy laminated plate. 


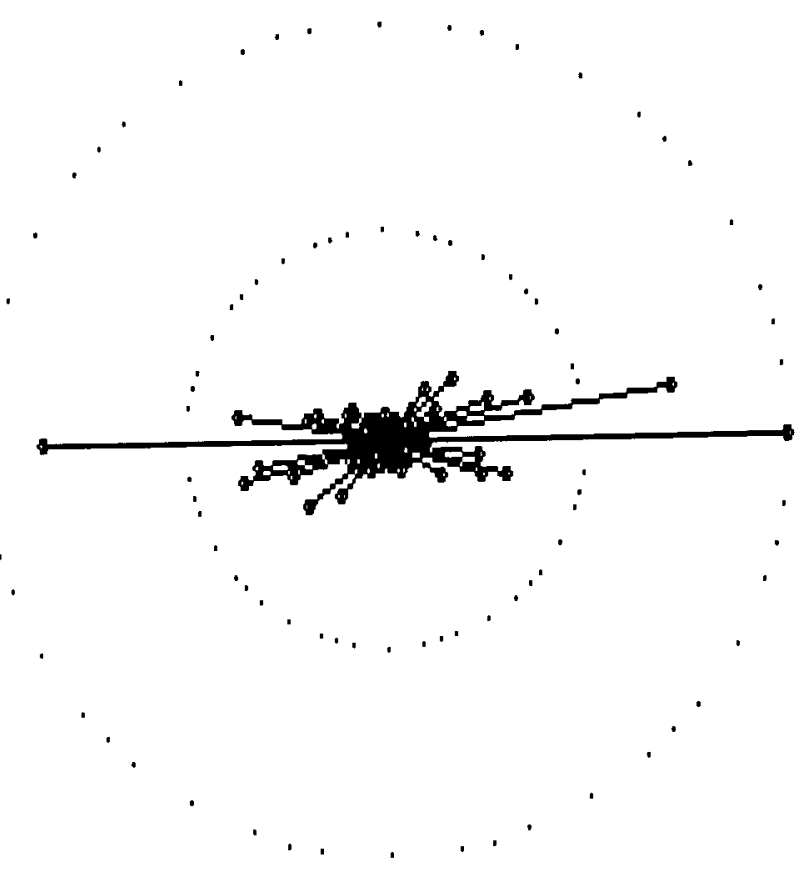

$[0 / 0 / 0 / 0] \quad A 2$

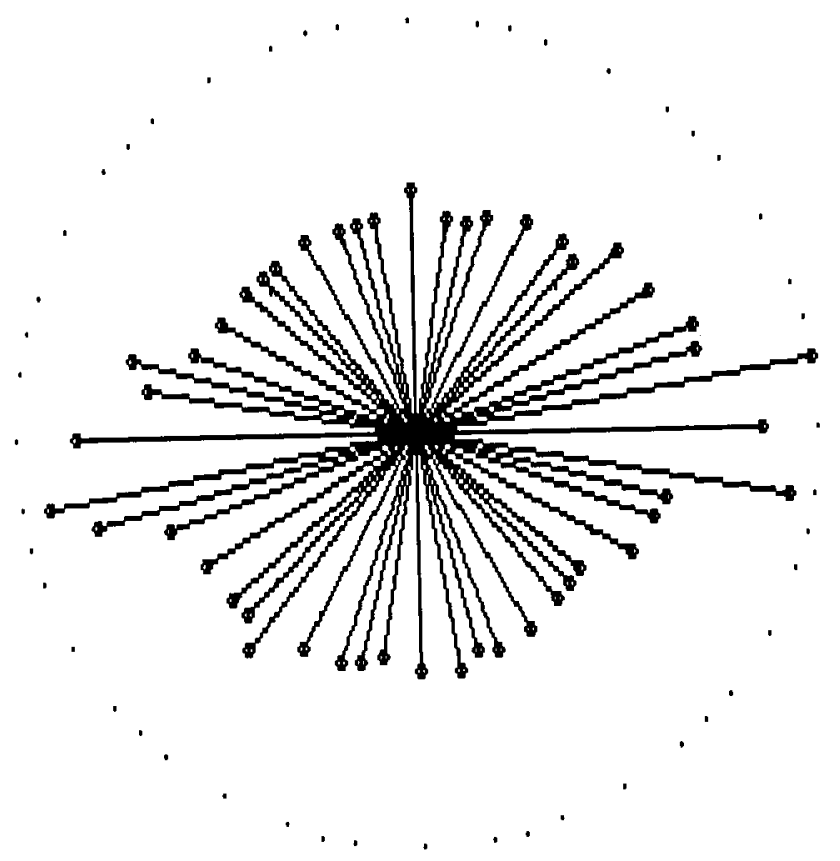

Fig. 15. AU versus azimuthal angle measured before and after central impact at the location of the source transducer for a $[0 / 0 / 0 / 0] \mathrm{Gr} / \mathrm{Ep}$ plate. a) A1 undamaged alone, b) A2 undamaged alone, 
$[0 / 0 / 0 / 0] \quad A 1(, 8,1,4)$

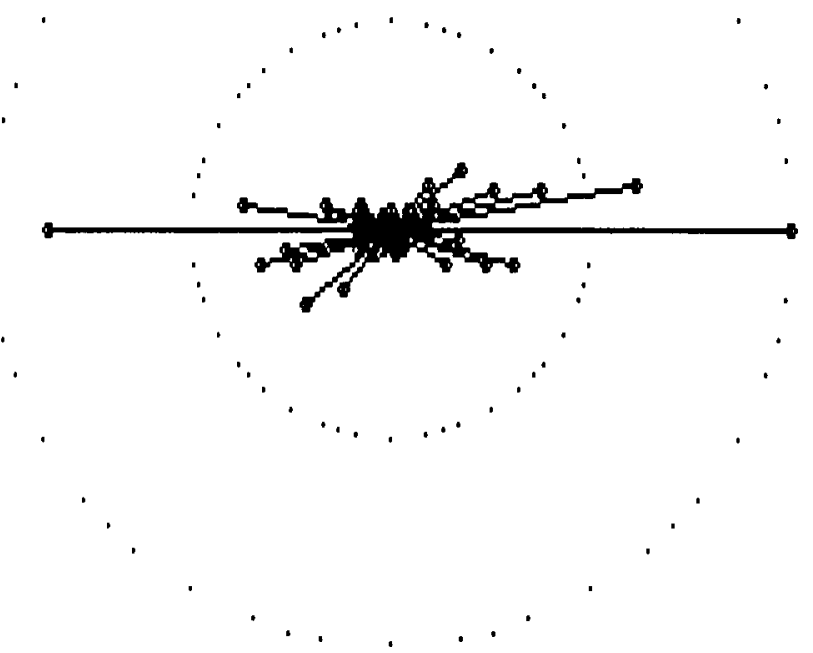

$[0 / 0 / 0 / 0] \quad A 1(3,2,3,6)$

Fig. 15. (cont.) c) A1 $(.8,1.4)$ undamaged, alone, d) A1(3.2,3.6) undamaged, alone. 
$[0 / 0 / 0 / 0]$ A1

undamaged

- af ter impact

Fig. 15. (cont.) e) A1 undamaged and after central impact, together; all A1 values are normalized with respect to largest value obtained before impact. The bold lines indicate the $\mathrm{A} 1$ values before impact and the circles indicate the post impact $\mathrm{A} 1$ values.

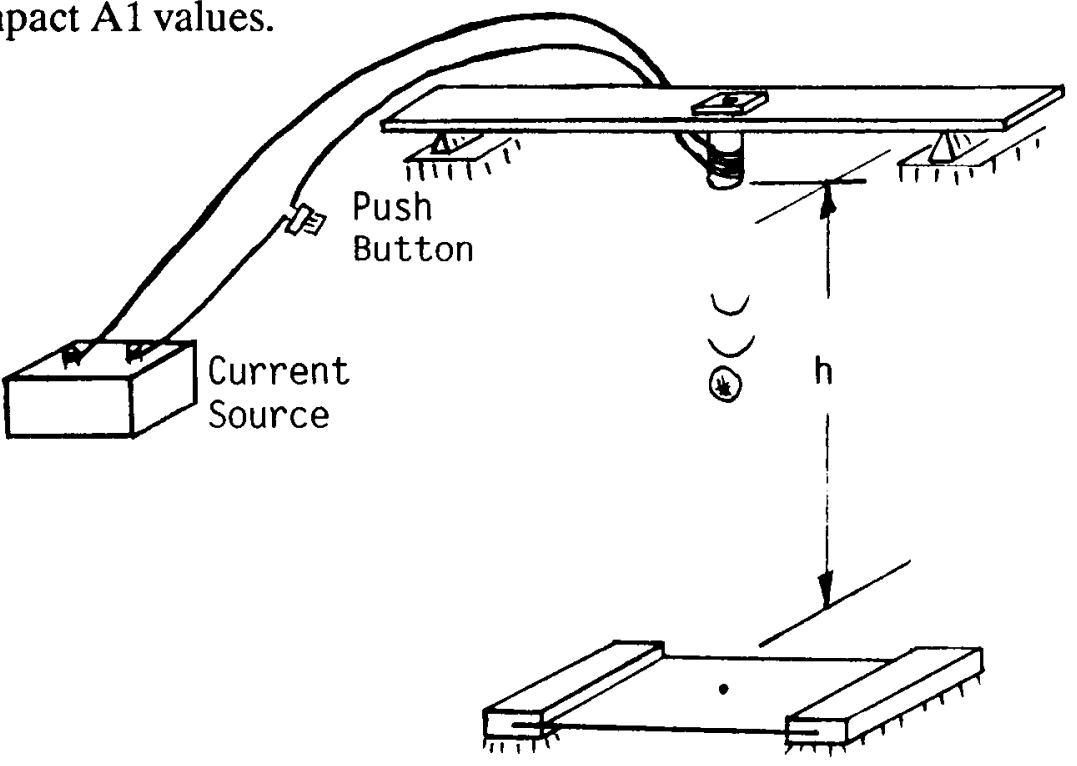

Fig. 16. Schematic diagram of the experimental arrangement used to carry out the impact loading of the specimens; $h \approx 10$ feet. 


\section{$[45 / 0 / 0 / 45]$}

By placing single $45^{\circ}$ plies on the outside of the fundamental element it was hoped to provide a situation of constraint intermediate to that of the crossply configuration considered next. Figure 17 is a plot of A1 versus azimuthal angle.

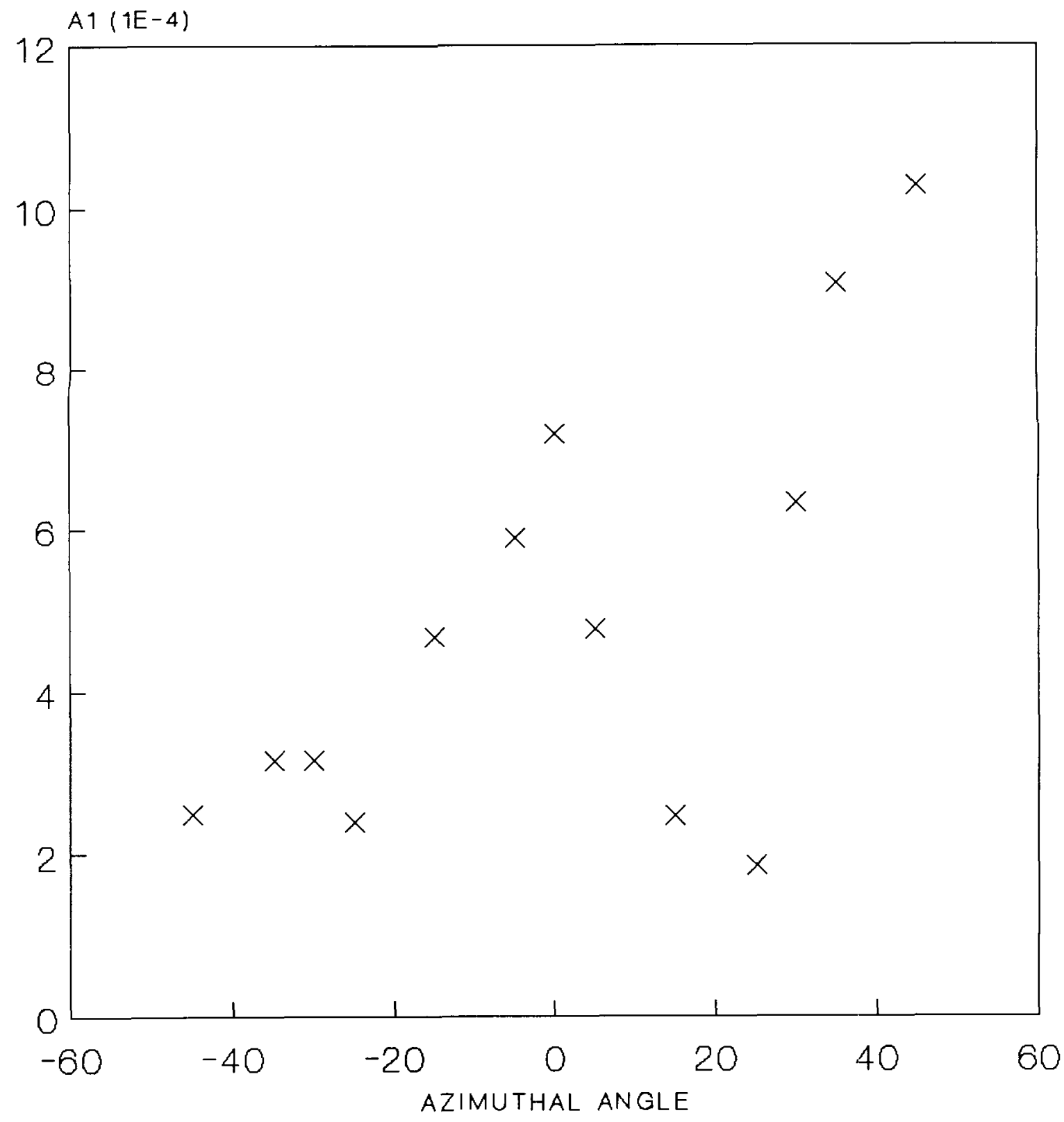

Fig. 17. A1 versus azimuthal angle for a [45/0]s $\mathrm{Gr} / \mathrm{Ep}$ laminate. 
Work is presently in progress to determine the AU response before and after impact for this ply configuration and also before and after cyclic loading to introduce matrix cracking, and after subsequently impacting these cyclically loaded specimens.

\section{$[0 / 90 / 90 / 0]$ and $[90 / 0 / 0 / 90]$}

By placing two $90^{\circ}$ plies next to the fundamental element the most extreme constraint in the transverse direction is obtained while the constraint in the $0^{\circ}$ direction is as small as possible for any neighboring ply orientation. Figure 18 displays the response of a [0/90/90/0] before and after impact, and Fig. 19 is the corresponding result for a [90/0/0/90] arrangement. It should be noted that the value of A1 in the direction that coincides with the outer ply orientation is $25 \%$ higher than for the direction that sponds to the internal ply fiber orientation.

\section{[0/90/90/0] A1 undamaged \\ - af ter impact}

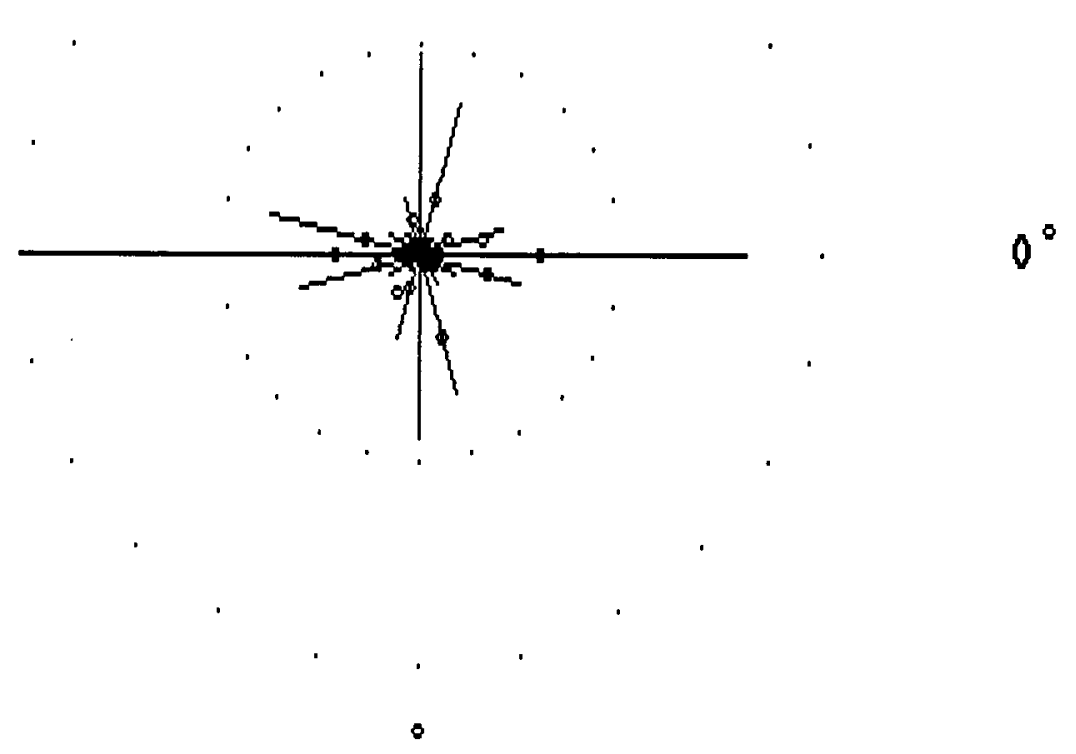

Fig. 18. A1 versus azimuthal angle measured before any mechanical loading, bold lines, after impact, (circles), of a [0/90/90/0]s Gr/Ep specimen. 


\section{[90/0/0/90] A1 undamaged \\ - af ter impact}

Fig. 19. A1 versus azimuthal angle measured before, (bold lines), any mechanical loading, after impact, (circles), of a [90/0/0/90]s Gr/Ep specimen.

In order to degrade the constraint of the fundamental element provided by the $90^{\circ}$ plies the specimens were cyclically loaded in tension with $\mathrm{R}=0.1$ in order to introduce matrix cracking. Evidence of the matrix cracking was confirmed by means of the edge replication method. (Penetrant enhanced radiography had been considered but was not used after it was determined that the penetrant affected subsequent AU measurements.) Figure 20 is a plot of $\mathrm{A} 1$ as a function of azimuthal angle typical of a [0/90/90/0] graphite fiber reinforced epoxy laminate before cyclic loading, after cyclic loading, and after impact following cyclic loading. A corresponding set for a [90/0/0/90] is shown in Fig. 21. Figures 22-25 are penetrant enhanced radiographs for [0/90/90/0] and [90/0/0/90] laminates that were impacted with and without prior cyclic loading; 1:1 and 2.5:1 versions are provided. Attention is drawn to the apparent correlation between the magnitude of the A1 measured before impact and the extent of damage development upon impact. Work is in progress to further investigate this phenomenon; [0/90]3s and [90/90/90/0]s laminates are being studied. 


\section{[0/90/90/0] A1}

undamaged

- af ter cycling

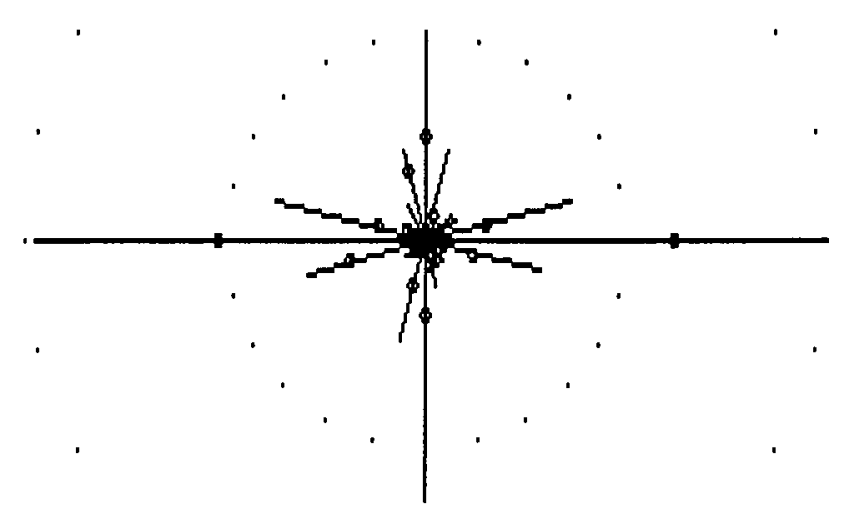

\section{[0/90/90/0] A1} - af ter cycling

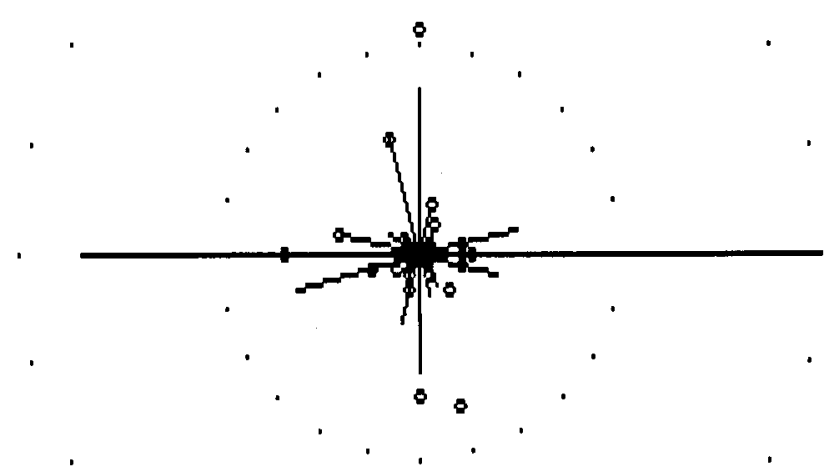

Fig. 20. a) A1 versus azimuthal angle measured before, (bold lines), any mechanical loading and after cyclic tensile loading, (circles), and b) before impact, (bold lines), and after impact, (circles), of a cyclicly loaded [0/90/90/0]s Gr/Ep specimen. 
[90/0/0/90] A1 undamaged

- af ter cycling

Fig. 21. a) A1 versus azimuthal angle measured before, (bold lines), any mechanical loading, and, after cyclic tensile loading, (circles); and after impact, of the cyclicly loaded [90/0/0/90]s Gr/Ep specimen no measureable change in A1 was detected.
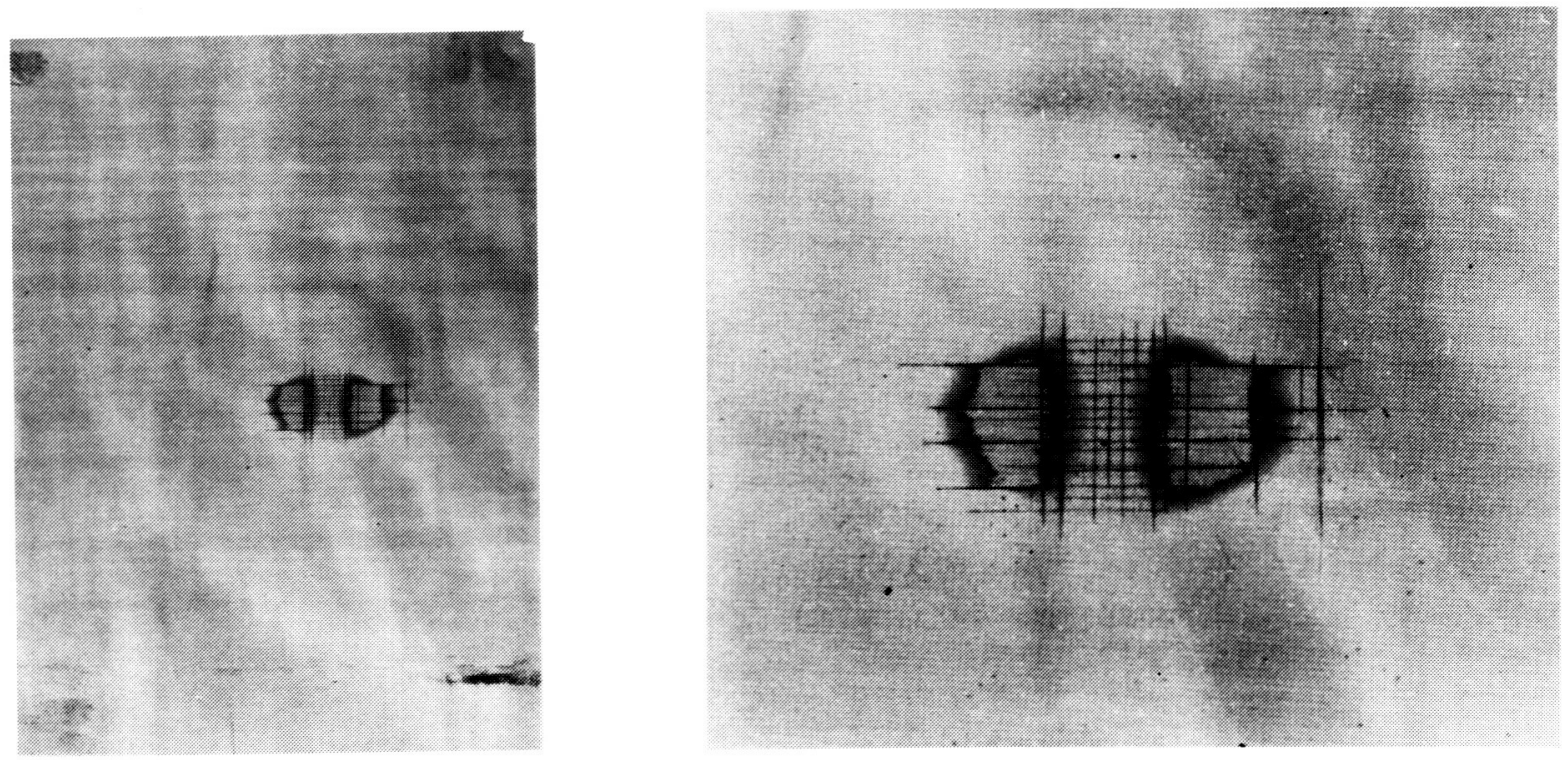

Fig. 22. Penetrant enhanced X-ray radiograph of the specimen used to obtain the data shown in Fig. 18. a) 1:1 magnification, b) enlargement of the region near the impact, 2.5:1 magnification. 


\section{ORIGINAL PAGE IS
OF POOR QUALTYY}
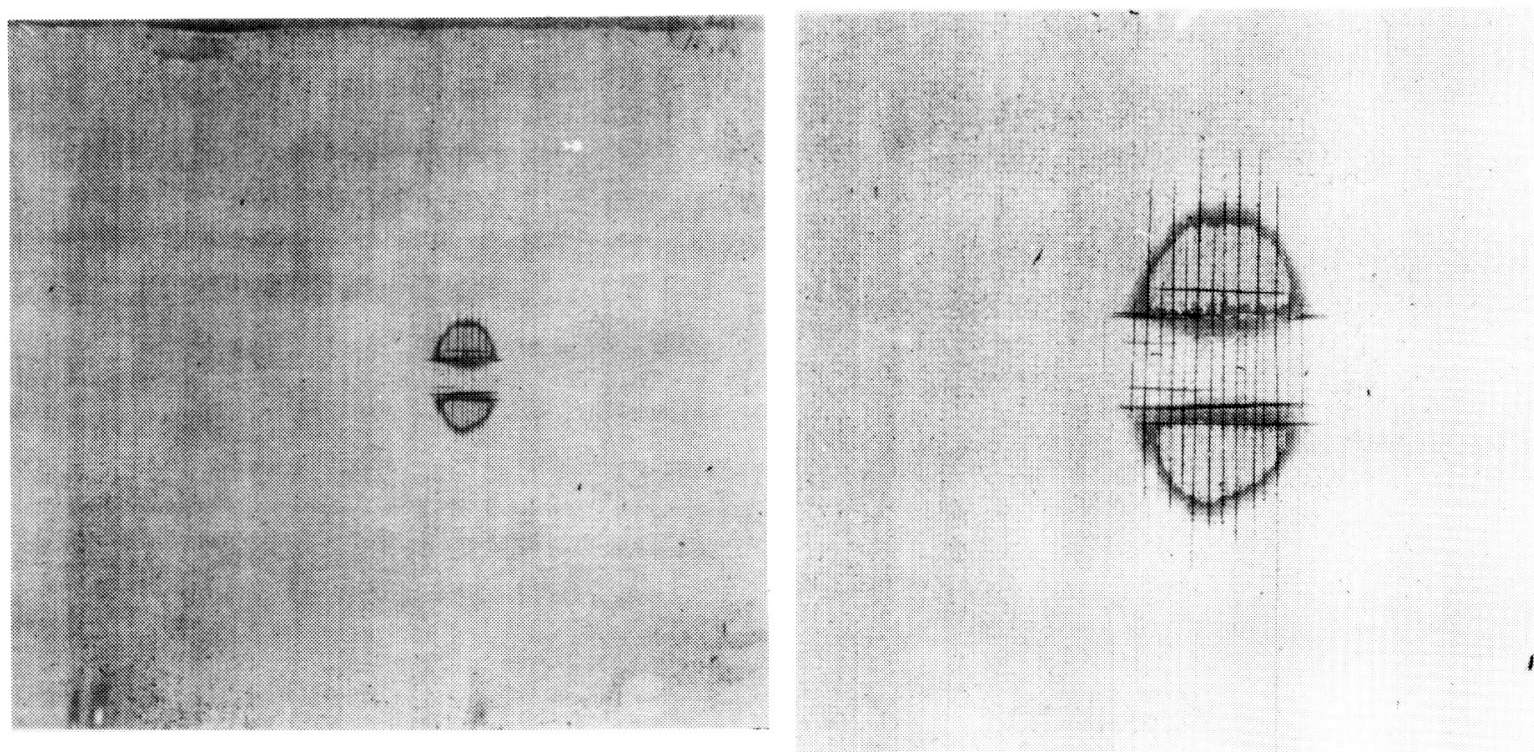

Fig. 23. Penetrant enhanced X-ray radiograph of the specimen used to obtain the data shown in Fig. 19. a) 1:1 magnification, b) enlargement of the region near the impact, 2.5:1 magnification.

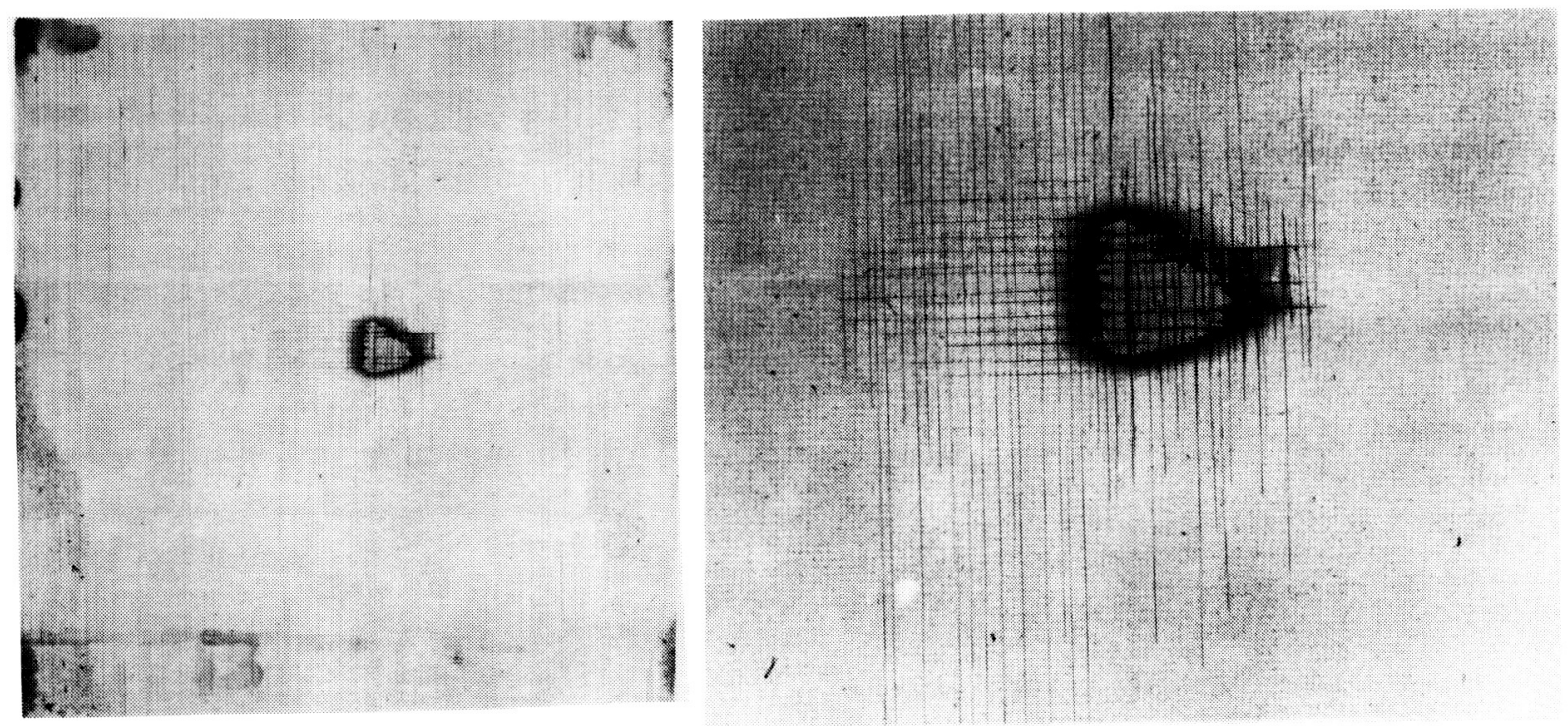

Fig. 24. Penetrant enhanced X-ray radiograph of the specimen used to obtain the data shown in Fig. 20. a) 1:1 magnification, b) enlargement of the region near the impact, 2.5:1 magnification. 

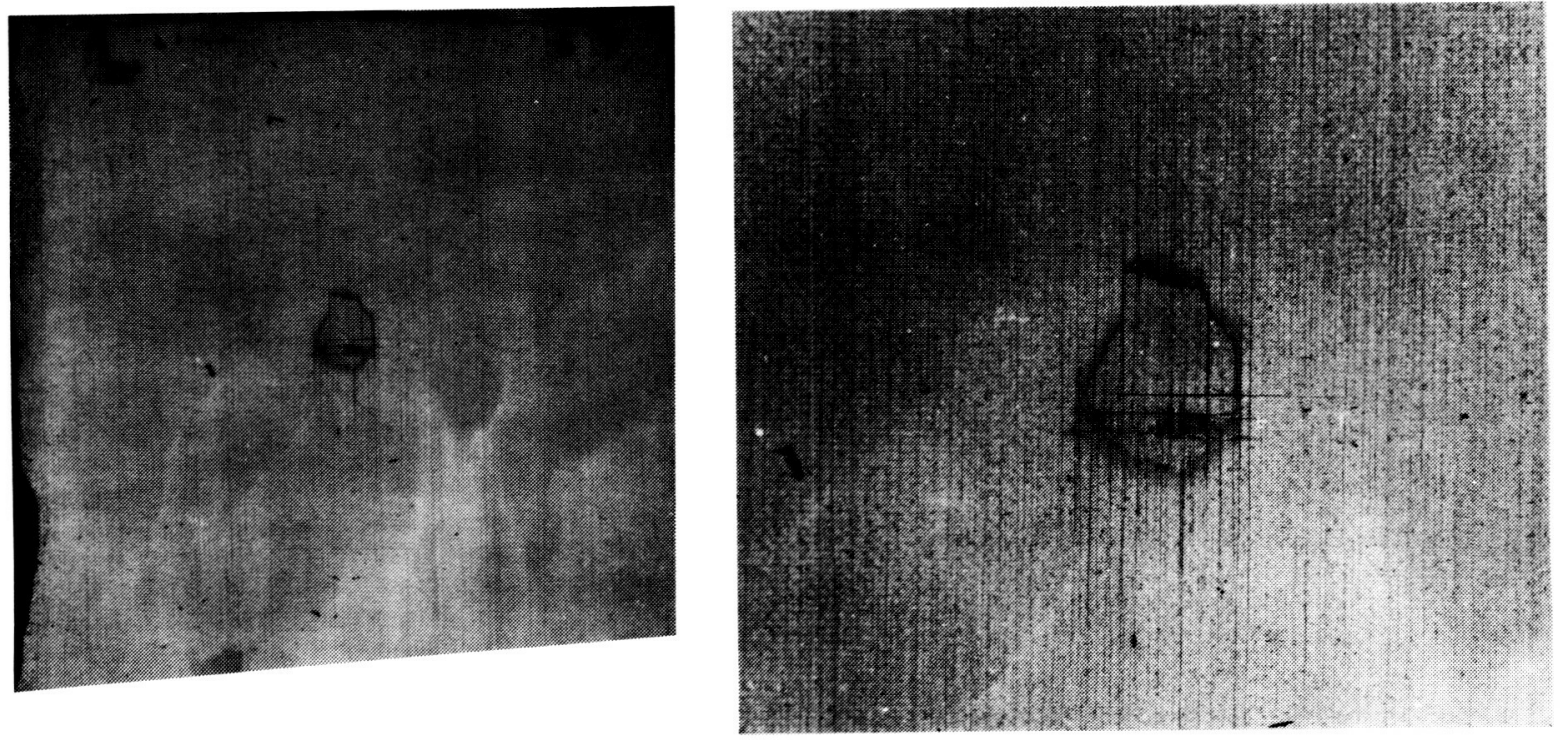

Fig. 25. Penetrant enhanced X-ray radiograph of the specimen used to obtain the data shown in Fig. 21. a) 1:1 magnification, b) enlargement of the region near the impact, 2.5:1 magnification.

Because dynamic load redistribution occurs during damage development it is believed that insight into the nature of this damage development is possible by considering the AU response of the material/component when the stress waves caused by the AU source are somewhat analogous to the damage induced stress waves. ${ }^{12,13}$ Work is continuing on interpreting the observed AU response in light of the various damage mechanisms that may occur as a result of a particular mechanical load experience.

ORICANAL PAGE IS

OF POOR QUALITY 


\section{AU EVALUATION OF CERAMIC COMPOSITE MATERIALS}

The need for material systems that will perform at elevated temperatures has turned additional attention to the ceramic fiber and ceramic matrix composite material candidates. Traditionally the toughness of monolithic ceramics has been low causing concern regarding their use in designs that demand durable performance. The inclusion of reinforcing fibers appears to offer a means of significantly improving the durability and thus allowing for exploitation of the high temperature capabilities of these materials. Since with other composite material systems the toughness attribute is also associated with distributed damage development it has been anticipated that $\mathrm{AU}$ for characterization of ceramic composite materials may be advantageous.

Although the shortcomings of monolithic ceramics are many, much work is being done to develop "tough" ceramics. Toughening can be achieved in several ways, including: the addition of a second phase of the same material, the addition of particles of another material to form a particulate composite, or the addition of whiskers or long fibers to create a fibrous composite material. The roles of these secondary materials are many, including:

1) To deflect an approaching crack, increasing the distance which it must travel through a specimen, thereby increasing the life of the material

2) To branch the crack, thereby eliminating the effects of one large crack propagating through the material

3) To reduce the stress concentration at the tip of the crack, thereby blunting it and slowing its growth

4) To dissipate fracture energy through fibers pulling out of the surrounding matrix material.

5) To prestress the material, with residual stress remaining after processing. 14

These composite materials have shown a much greater strain energy to failure compared to their monolithic counterparts. In many cases material properties, such as strain to failure and ultimate strength, have been increased significantly.

\section{Literature Survey}

Imperfection Detection- Unfortunately for the researcher, very little information has appeared in the literature regarding NDT of ceramic matrix composite materials. It seems to mean that either research in this area is badly lacking or the work that has been done is considered proprietary. Most of the information must, therefore, be 
drawn from the studies of monolithic ceramics and then must be applied to ceramic matrix composite materials.

The available literature leads to the area of flaw detection and critical flaw sizes for a monolithic ceramic materials. The size of the largest imperfection which can exist in a component and not cause catastrophic failure is considered to be the critical flaw size. Much of the NDT research has, therefore, been centered on locating imperfections and determining the smallest flaws which can be accurately found by various NDT techniques.

The purpose of using reinforcement in ceramic materials is, of course, to reduce sensitivity of the material performance to small imperfections. One goal of the researcher should be to identify the smallest strength controlling flaw which may exist in a particular material. Detection techniques should then be developed to locate any imperfections larger than this size.

The critical flaw size in some monolithic materials has been reported to be in the 10 micrometer range. ${ }^{15}$ NDT techniques applied to monolithic ceramics have been reported which are able to locate flaws in the tens of micrometers range, so these techniques should be easily applied to ceramic composites. 16

One problem of concern is that most studies in this area use imperfections imbedded in samples by the investigators. The usefulness of the techniques becomes questionable when applied to real ceramic components, out of laboratory conditions. Another problem is the time required to perform the inspection; it may take hours to fully inspect even a small region for microscopic imperfections.

Techniques which are of use in locating and sizing of small imperfections include high frequency ultrasonic scans, ultrasonic scattering and attenuation measurements, and microfocus radiography. $15-18$

Porosity and Density- Other imperfections which are desirable to locate in ceramic materials are large pores and density variations, that would have a negative effect on the strength or toughness of the material.

Most pores and density variations result from numerous process variables. New processes for the production of ceramic matrix composites are being developed which lower density variations and porosity. 
One technique being developed for the production of ceramic matrix composites is Chemical Vapor Infiltration (CVI). ${ }^{19}$ In this technique, a chemical vapor containing molecules of the matrix material is passed through a preformed mesh of fibers. In the presence of heat and pressure, the matrix is deposited uniformly on the ceramic fibers. The process takes hours or days to complete, but the resulting matrix is significantly more uniform and dense than composites produced by other methods.

Composites produced by CVI have been reported to have theoretical densities as high as $85-90 \%, 20,21$ however, a large number of pores may be distributed throughout the composite. Oak Ridge National Laboratories reports that pore sizes as large as several hundred micrometers exist within these composites. It has been hypothesized that further densification will have little beneficial effect on strength and toughness of these materials. 22

Several other processing methods are mentioned in the available literature including reaction bonding, polymer precursor synthesis, and sol-gel techniques, ${ }^{23}$ however, the prevalent processing method is hot pressing. It is difficult to produce uniform material using this method; large variations in the material density after processing have been reported. These variation will have a pronounced effect on the properties of the finished material. Such inhomogeneities may be produced by any number of processing problems (such as irregularities in raw materials, hot pressing variations such as time, temperature and pressure).

Large pores often remain in the material even after hot pressing. One reason for this is because the reinforcement fibers inhibit the flow of viscous glass (or other matrix material). The flowing matrix material may be restrained from flowing into certain areas of the mesh, thereby leaving voids and pores.

NDT techniques have proven to be useful in several ways in this area. Location of pores larger than a critical flaw size would be necessary to assure that a component would be trustworthy in service. High frequency ultrasonic techniques and microfocus radiography could prove to be effect in locating and sizing such flaws.

Location and characterization of clusters of small pores or density variations would probably be more useful in the investigation of ceramic composite materials because of the decreased dependency upon single imperfections. Ultrasonic ing and attenuation measurements have been used to measure density gradients in the monolithic ceramic materials. Ultrasonic velocity measurements have been applied to 
monolithic ceramics and material densities variations as small as $2 \%$ have been identified. X-ray techniques have also been used. These techniques may also be applicable to ceramic matrix composite materials. $15,16,18,24$

Matrix Variation- Most matrix materials for ceramic matrix composites have been ceramics which have been produced in monolithic form at one time, however, required toughening or strengthening. The condition of the matrix material is of as great an importance in composite materials as the condition of the reinforcing fibers.

Variations in grain size may have an undesirable effect on the properties of a ceramic. An oversized grain may be the source of a crack or if too large, the grain may exceed the critical flaw size.

The existence of different phases of the matrix ceramic can greatly change the properties of the resultant composite. The existence of secondary phases of the ceramic matrix could have beneficial or undesirable effects on the material. In some materials inclusions of a secondary phase are considered to be the toughening agent the inclusions deflect approaching cracks. The secondary phase may also degrade the overall performance. Secondary phase inclusions may be crack initiation points; microcracks may occur in the two phase matrix at a lower load than would be expected in single phase matrices.

Residual Stress- As in other composite systems, residual stresses are present in ceramic matrix composite materials due to the unequal coefficients of thermal expansion between the various components of the composite system. The materials are processed at a high temperature, and after cooling, the constituents of the composite system attempt to shrink different amount, therefore, creating residual stresses.

Residual stresses may also be present due to other processing techniques, such as rolling or pressing of the material. Machining of components may also leave stresses in the material. If the residual stress levels within the composite are large enough, microcracking of the matrix will result.

An understanding of these residual stress levels will be important in the design and analysis of structures constructed of advanced composite materials. A measurement of these stress levels would prove to be of great use when determining the suitability of a part for service. $16,25,26$ 
Anisotropy- Both whisker and fiber reinforced (long fibers) composite materials will be anisotropic to a certain degree. On the other hand, randomly oriented particulate composites can usually be treated theoretically as statistically isotropic. The variation of mechanical properties in various directions may result from fiber orientation, hot pressing, or rolling of the ceramic composite during preparation.

An understanding of the degree of anisotropy is required for proper design and use of a material system. A measure of the relative material properties in various directions would be of great use. This measurement may prove to be difficult to accurately determine. A NDT method to determine these properties, or at least give a qualitative assessment of their variation, would be useful.

Presently, mechanical testing is the dominant method of determining material properties in anisotropic specimens. Ultrasonic velocity measurement have been used on ceramic materials to determine anisotropy. 15,27 Acousto-Ultrasonic measurements have been shown to have a direct correlation to direction in other anisotropic materials. 10

Fiber Distribution- Homogeneous fiber distribution throughout a matrix material is an important quality in a composite material system. It is not uncommon to have areas of fiber or whisker concentration or sparsity in these materials. These regions would obviously have detrimental effects on the performance of the material. The location and measurement of degree of concentration variation could be used in quality control systems. A measurement of the effect of these inhomogeneities on the overall material characteristics would be of even greater use.

Ultrasonic velocity tests and attenuation measurements could be useful in locating these imperfections. X-ray methods would also be useful in locating and sizing the regions of concern. Yet, with all of these methods it left to the NDT inspector to determine the effect these regions may have on the performance of the material. AU would yield a interactive measurement of the material characteristics and could be used to determine if the material was suitable for use.

Fiber Degradation- Several fibers used for reinforcement of a composite systems have been shown to degrade in the presence of high temperatures and oxidizing environments. ${ }^{19,28}$ These factors may exist during material processing or while in service. 
The matrix material of a ceramic composite material generally protects the fibers from the surrounding atmosphere. However, in service, microcracks may allow exposure to degrading atmospheres.

For example, it has been shown that $\mathrm{SiC}$ fibers may begin degrading at temperatures as low as $1000^{\circ} \mathrm{C}$. An oxide scale forms on the fiber surface and the fiber becomes extremely notch sensitive. After such exposure, fiber strength may be reduced by as much as $75 \% .29$ The degradation of the fibers in association with matrix microcracking will greatly reduce the stiffness and strength of a material.

It is questionable if X-ray methods would be able to show fiber degradation, however, fiber breakage could probably be noticed. A reduction in stiffness and strength would be found if the part were loaded or proof tested, however, these methods may advance damage which already exists within the structure. AU could possibly show the extend of fiber degradation as well as the resulting material characteristics.

Damage Development- A ceramic matrix which has been reinforced with continuous fibers not only has decreased sensitivity to microscopic flaws, but also has the ability to sustain damage without catastrophic structural failure. It has been shown that ceramic matrix composite materials with long fibers for reinforcement have a general failure pattern: elastic behavior until the formation of microcracks within the matrix, increasing strain levels while microcracking appears throughout the matrix, and failure with a single predominant crack through the thickness of the specimen. $26,30,31$

The detection of the onset of non-elastic behavior would be of great use to the designer. Acoustic emission monitored during testing may be used to locate the load at which the specimen begins to crack. This information would allow for parts to be design to stay below the load levels that produce such cracks.

This is of little use when considering composite components which have been used in service or those which may have been exposed to fatigue loading. Fatigue type loads would tend to produce microcracks within the matrix, however, a further study of the fatigue damage development is needed.

A measure of the material integrity after some load history is necessary. Such a measure may be made nondestructively on ceramic matrix composite materials through the application of AU. The stress wave which travels through the composite 
specimen interacts with the material and any damage which may be present, thereby resulting in a measure of the material's performance. This quantitative measure of the material characteristics would eliminate the dependence upon subjective decision required when other NDT measurement techniques are use.

Fiber-Matrix Interface- It has been stated that the behavior of ceramic matrix composite material is highly dependent upon the characteristics of the fiber matrix interface. $21,25,26,28,29,32$ In a composite in which the constituents are of the same composition, any cracks which propagate through the material tend to "see" only one material, and therefore, the material acts as if it were monolithic. These materials generally exhibit very brittle behavior and show little tolerance to damage. A composite material in which a strong "bond" between the fibers and the matrix exist will also result in a very brittle composite - the fibers will break, rather than pull out of the matrix. These composites offer little or no resistance to a propagating crack. A frictional interface results in a better performing composite. The fibers can pull out or deflect approaching cracks, thereby increasing the energy needed to fracture the material.

Several methods of altering the fiber matrix interface to produce a better performing material are used. The most successful method seems to be fiber coatings. The fibers are coated with a thin layer of another material which creates a frictional bond with the matrix. Because the fiber-matrix interface has a pronounced effect on the performance of the composite, this area deserves much more research attention.

In-Process NDT- It has been reported that NDT has been used to determine modifications necessary to improve the quality and reliability of ceramics and ceramic matrix composites. ${ }^{15,18,33,34}$ Various techniques have been used including radiography and ultrasonic scans.

Testing of specimens has been done at various stages during processing, including NDT of raw materials (powders and fibers), green state ceramics, and finished materials. Changes in production that have been suggested through nondestructive evaluation have reduced density variations, porosity, fiber misalignment, and fiber concentrations. 


\section{Correlation With Ultrasonic C-scan Results}

Some fiber reinforced borosilicate glass matrix material has been provide, for study, by Martin Marietta. Prior to shipping these panels the NDE Group at the Research and Development Center of Martin Marietta Corporation examined the materials using ultrasonic C-scan. AU evaluation of these panels at VPISU has provided some preliminary results.

The panels were examined using 0.5 in. diameter $5 \mathrm{MHz}$ transducers described earlier as source and detector. The transducer pair was kept one inch apart while begin at one edge of the 4 in. $x 4$ in. plates. Measurements were then made at positions every $0.5 \mathrm{in}$. travelling in a direction parallel to the line through the transducers centers. When a transducer reached the edge, the assembly was indexed perpendicuperpendicular to this line of motion, $0.5 \mathrm{in}$. and the measurements were again made at 0.5 in intervals. The signal was captured and analyzed in order to determine the value of A1 for each signal detected. The A1 values were assigned to the locations midway between the transducers for each location. Since the transducers were not allowed to extend off the plate and because of their 0.5 in. diameter the AU measurement area was 3.5 in. $x 2.5$ in.

Figure 26 a is a "topographical" plot of the measure A1 for a Corning 7740 borosilicate glass plate reinforced with hand chopped Nicalon $\mathrm{SiC}$ fiber cloth. Figure $26 \mathrm{~b}$ is the ultrasonic $\mathrm{C}$-scan obtained using $2.25 \mathrm{MHz}$ transducers and squirters. Figure 27 a is a "topographical" plot of the measure A1 for a Corning 7740 borosilicate glass plate reinforced with hand chopped graphite Fiberite W-341 cloth. Figure $27 \mathrm{~b}$ is the ultrasonic $\mathrm{C}$-scan obtained using $2.25 \mathrm{MHz}$ transducers and squirters. Figure 28 is a wire frame plot, of the $\mathrm{A} 1$ values shown in Fig. 27. (A Corning 7740 borosilicate glass plate with 6 plies of graphite fiber, Fiberite W-341 cloth, was also provided. Martin Marietta was unable to ultrasonically scan the plate, and the initial efforts to evaluate the AU response were inconclusive.)

Work is continuing in an effort to examine the correlation of AU behavior and mechanical performance for this class of materials. 


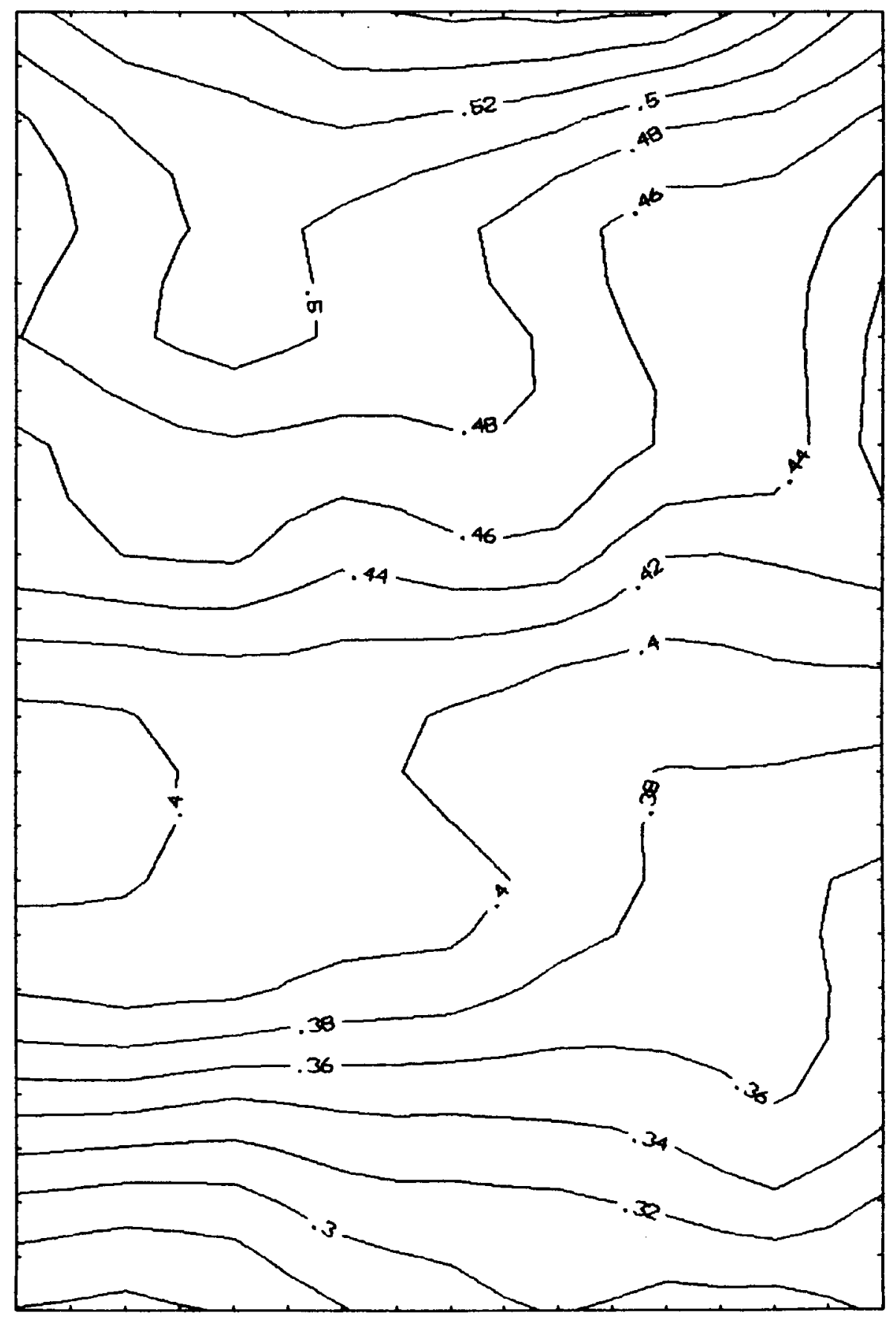

Fig. 26. Corning 7740 borosilicate glass 4 in. $x$ 4in. plate reinforced with hand chopped Nicalon SiC fiber cloth a) topographical presentation of A1, 


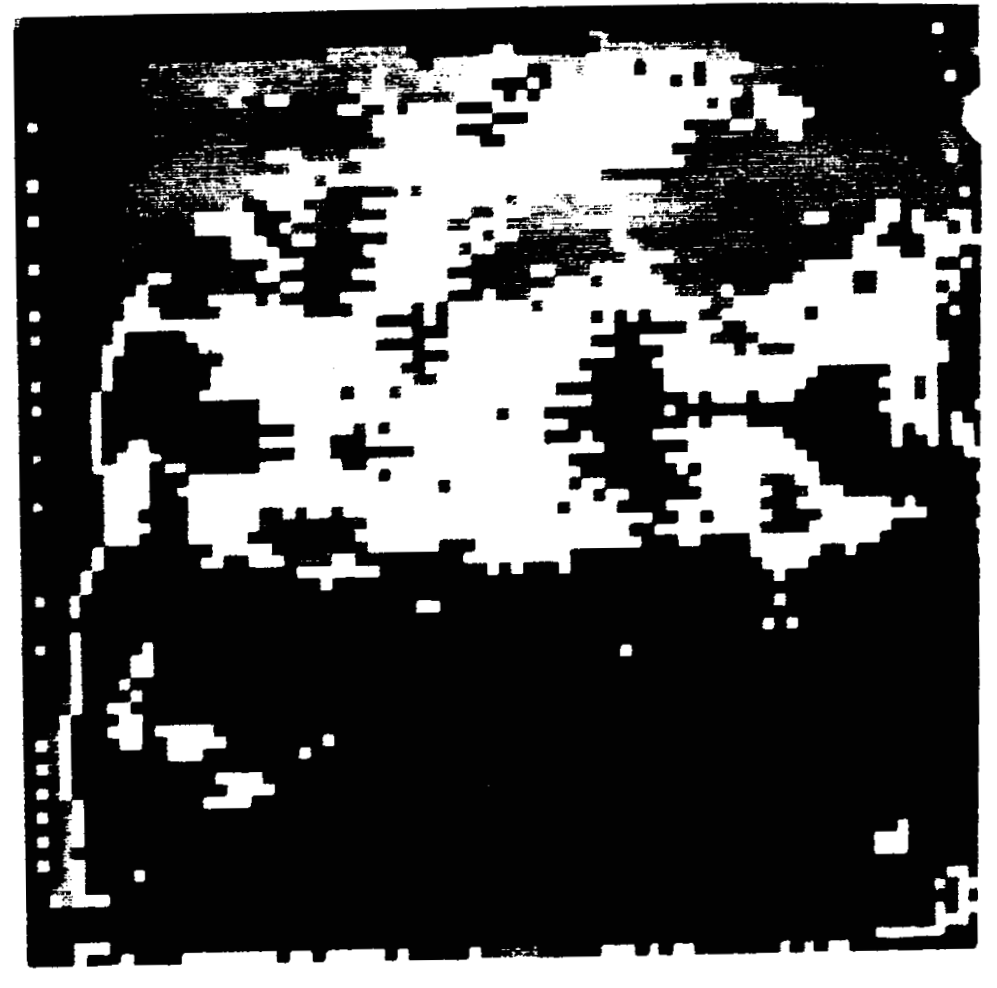

\section{ORIGINAL PAGE IS OF POOR QUALITY}

Fig. 26. (cont.) b) "gray scale copy" of the color normal incidence ultrasonic C-scan using 2.25 MHz transducers and squirters. (Provided by Martin Marietta) 


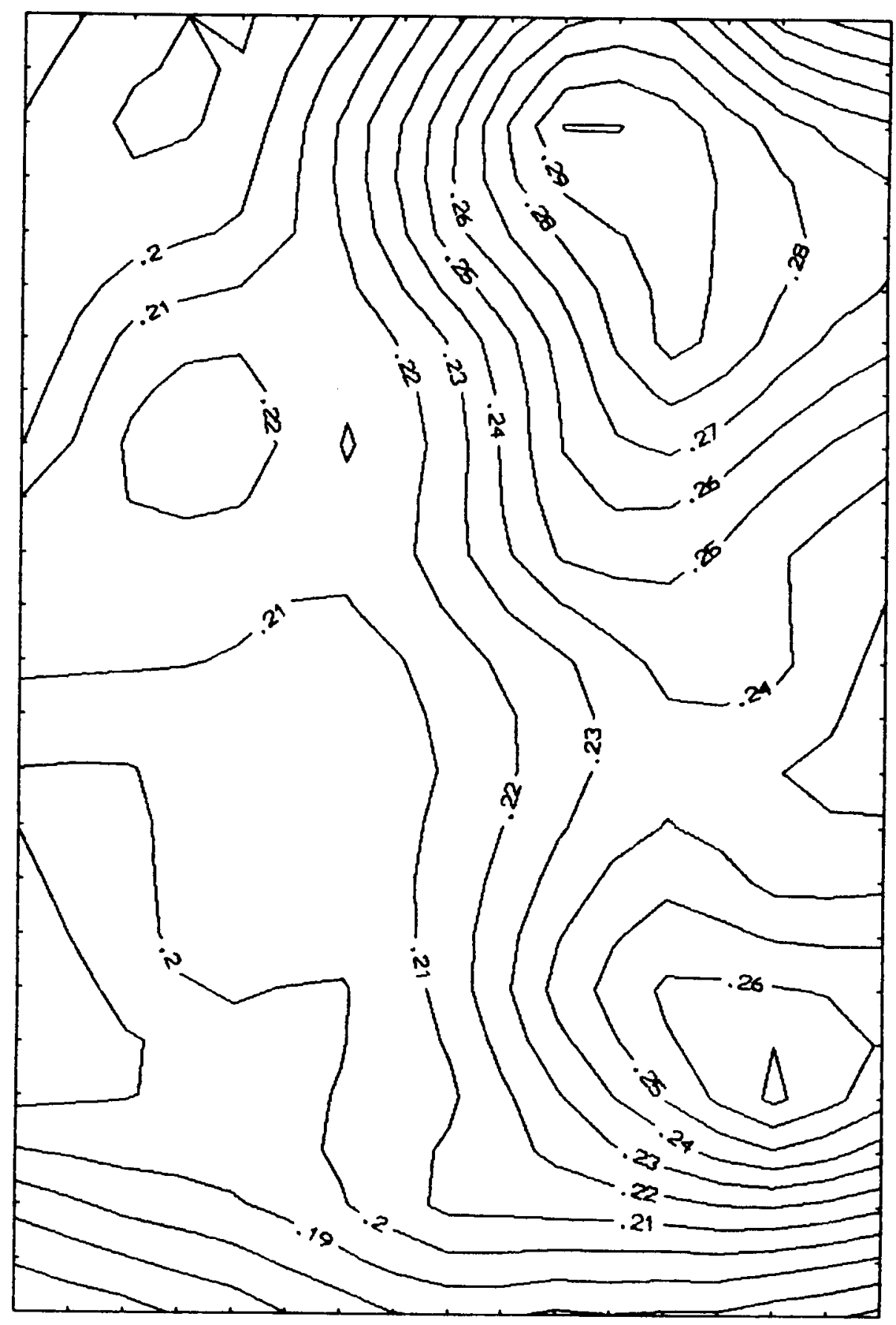

Fig. 27. Corning 7740 borosilicate glass 4 in. $x 4$ in. plate reinforced with hand chopped graphite fiber cloth, Fiberite W-341, a) topographical presentation of $\mathrm{A} 1$, 


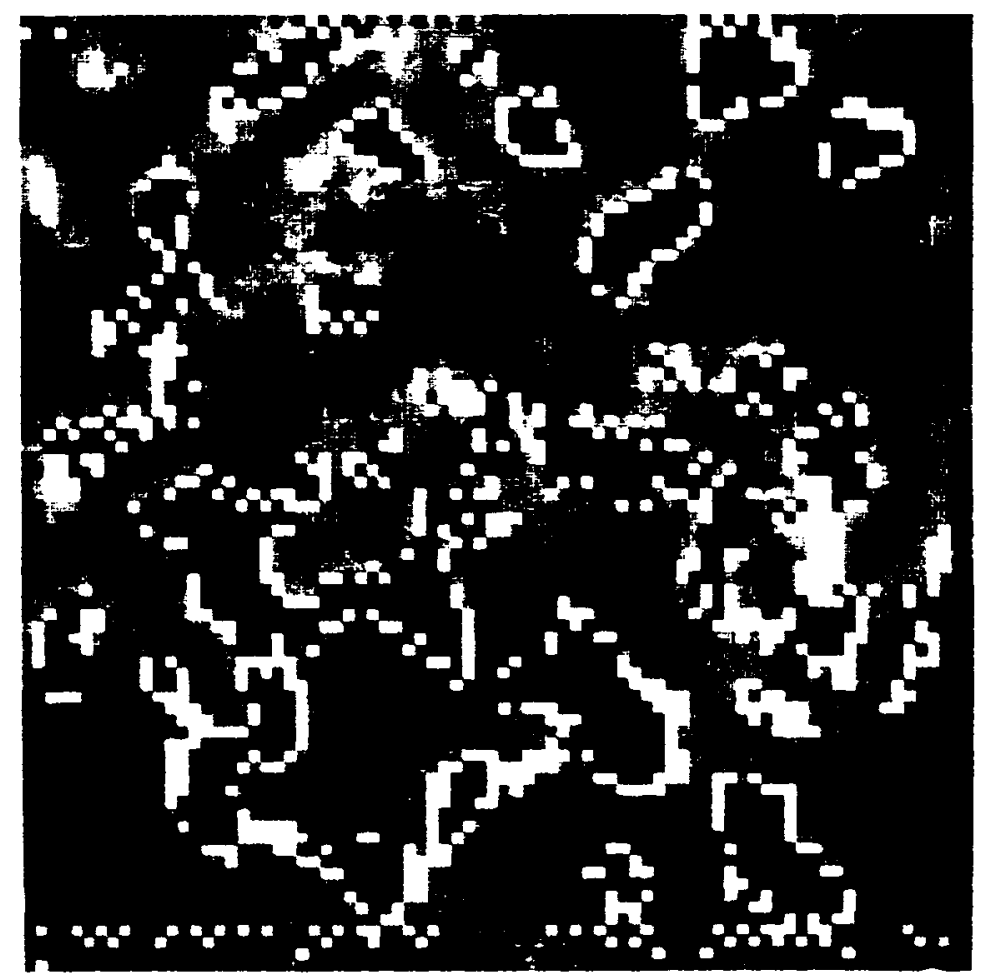

Fig. 27. (cont.) b) "gray scale copy" of the color normal incidence ultrasonic C-scan using $2.25 \mathrm{MHz}$ transducers and squirters. (Provided by Martin Marietta) 


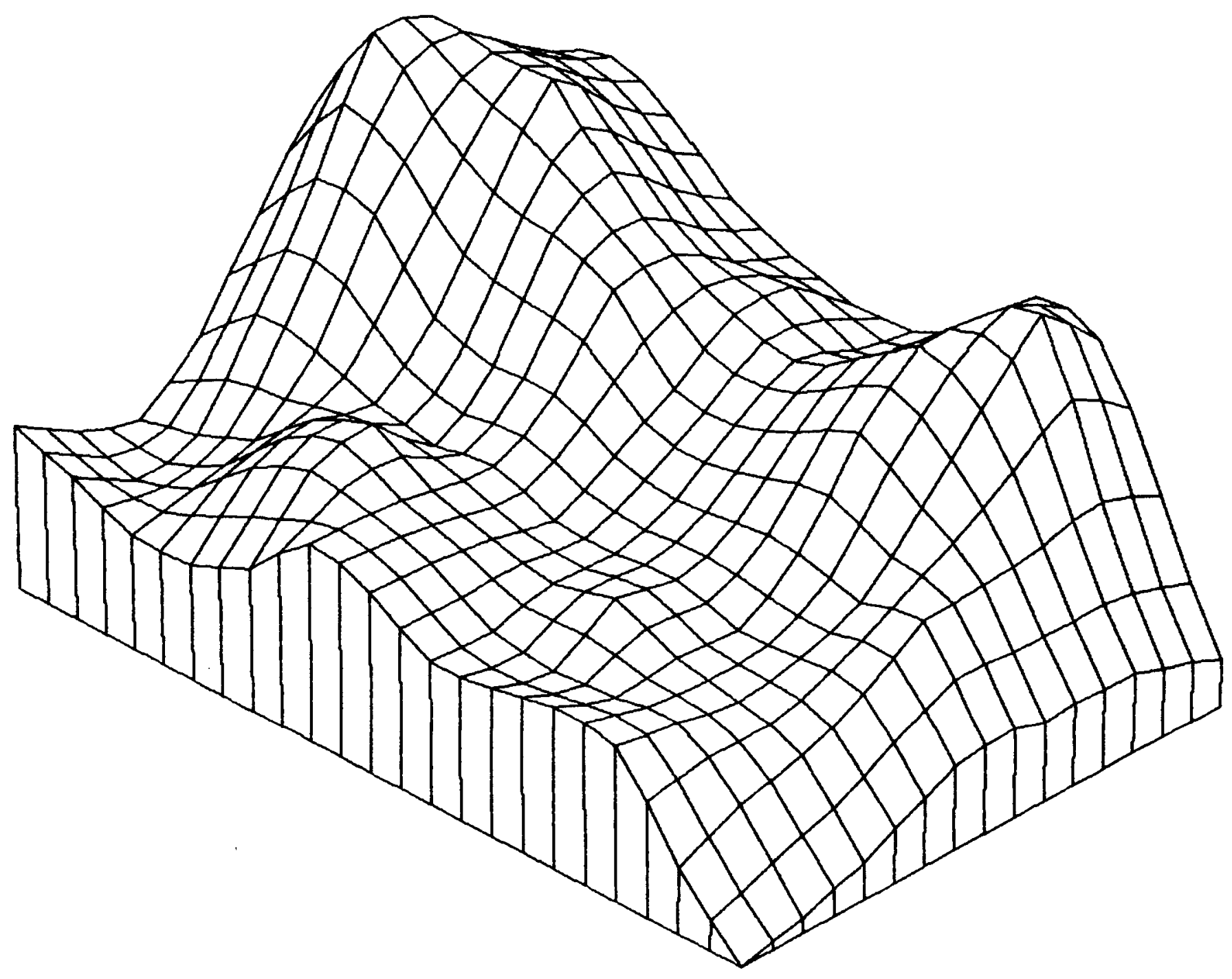

Fig. 28. "Wire frame" plot presentation of A1 values presented in Fig. 27a. 


\section{LASER IN/OUT}

\section{Laser Interferometric Detection}

In order to apply the AU NDE method in some situations noncontact source generation and ultrasonic detection are required because of constraints with regard to use of acoustic couplant or geometric details of the component. Although several possibilities are available including EMATs and transducers coupled by means of air or elastomeric materials, special consideration has been given to pulsed laser generation of mechanical disturbances and optical detection of transient surface displacements. Previously optical systems capable of measuring in-plane ${ }^{35}$ and out-ofplane $^{36}$ displacement were developed. Recently an optical arrangement that integrates these measurement procedures in order to allow for making both measurements without moving the specimen has been set up in the Acousto-Ultrasonics Facility at VPISU. Figure 29 is a schematic of this optical arrangement.

\section{Laser In}

The acquisition of a pulsed laser system has made it possible to consider pulsed laser generated mechanical excitation as an AU source. Figure 5 is an example of the signal obtained using such a source as detected by an acoustic emission sensor. The use of such a means of excitation however raises a number of fundamental questions including:

1) What is the nature of the interaction between the laser generated excitation and the material, both surface and subsurface?

2) What level of excitation is required to provide a detectable signal?

3) How may the nature of the excitation be controlled or modified?

Work directed at answering these questions is in progress. 


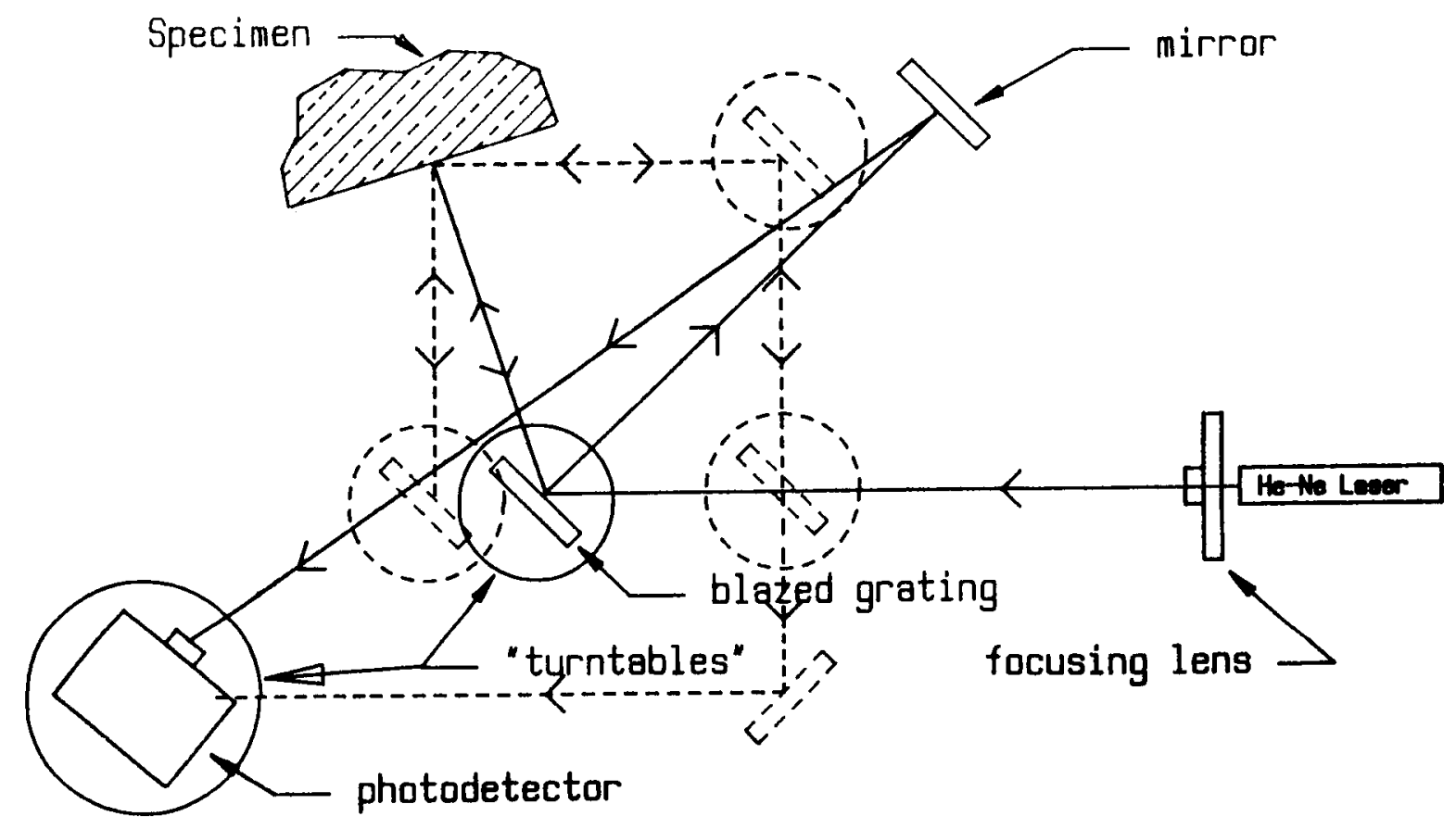

Fig. 29. Schematic of combined in-plane and out-of-plane transient displacement optical measurement arrangement. The solid lines represent the positions for optical elements of the out-of-plane detection setup, while the dashed lines indicate the optical components used to detect in-plane displacement. 


\section{REFERENCES}

1. A. Vary and K. J. Bowles, " An Ultrasonic-Acoustic Technique for Nondestructive Evaluation of Fiber Composite Quality," Polymer Engineering and Science, 19(5), 1979, pp. 373-376.

2. J. H. Williams, Jr., H. Karagülle, and S. S. Lee, "Ultrasonic Input-Output for Transmitting and Receiving Longitudinal Transducers Coupled to the Same Face of Isotropic Elastic Plate," Materials Evaluation, 40(6), 1982, pp. 655-662.

3. H. E. Kautz, "Ray Propagation Path Analysis of Acousto-Ultrasonic Signals in Composites," Acousto-Ultrasonics: Theory and Application ed. J. C. Duke, Jr., Plenum, New York (1988), pp. 126-142.

4. J. C. Duke, Jr., E. G. Henneke, II, and W. W. Stinchcomb, Ultrasonic Stress Wave Characterization of Composite Materials, NASA CR-3976, NASA, Cleveland, 1986.

5. E. G. Williams, H. D. Dardy, and R. G. Fink, "A technique for measurement of structure-borne intensity in plates," J. Acoust. Soc. Am. 78(4), 1985, pp. 2061-2068.

6. P. J. Latimer and H. L. Whaley, "Electromagnetic Transducers for Generation and Detection of Ultrasonic Waves," Acousto-Ultrasonics: Theory and Application ed. J. C. Duke, Jr., Plenum, New York (1988), pp.209-220.

7. M. T. Kiernan and J. C. Duke, Jr., "PC Analysis of an Acousto-Ultrasonic Signal," Materials Evaluation, 46(10), 1988.

8. S. O. Rice, "Mathematical Analysis of Random Noise," Bell System Technical Journal, Vol. 23, 1944, pp. 282-332, and Vol. 24, 1945, pp. 46-156; reprinted in Selected Papers on Noise and Stochastic Processes, ed. N. Wax, Dover, New York, 1954.

9. R. Talreja, A. Govada, and E. G. Henneke, II, "Quantitative Assessment of Damage Growth in Graphite/Epoxy Laminates by Acousto-Ultrasonic Measurements," Review of Progress in Quantitative Nondestructive Evaluation, Vol. 3B, ed. D. O. Thompson and D. E. Chimenti, Plenum Press, New York, (1984), pp.1099-1106.

10. M. T. Kiernan and J. C. Duke, Jr., "Acousto-Ultrasonics as a Monitor of Material Anisotropy," Materials Evaluation, 46(7), 1988, pp.1105-1113.

11. A. Madhav and J. A. Nachlas, "Statistical Evalaution of Quality in Composites Using Stress Wave Factor Technique," Acousto-Ultrasonics: Theory and Application, ed. J. C. Duke, Jr., Plenum, New York (1988), pp. 165-176.

12. J. C. Duke, Jr. and M. T. Kiernan, "Predicting Damage Development in Composite Materials Based on Acousto-Ultrasonic Evaluation," Acousto-Ultrasonics: Theory and Application, ed. J. C. Duke, Jr., Plenum, New York (1988).

13. J. C. Duke, Jr. and M. T. Kiernan, "Impact Damage Development in Damaged Composite Materials," Proceedings of the 4th US-Japan Conference on Composite Materials, American Society of Composites, Dayton (1988).

14. R. W. Rice, "Mechanisms of Toughening in Ceramic Matrix Composites," Ceramic Engineering and Science Proceedings, Vol 2, July/August 1981.

15. D. Kupperman and H. Karplus, "Ultrasonic Wave Propagation Characteristics of Green Ceramics," Ceramic Bulletin, No. 12, 1984.

16. H. Berger and D. Kupperman, "Microradiography to Charaterize Structural Ceramics," Materials Evaluation, 43, Feb. 1985. 
17. A. Hecht, E. Neumann and P. Rose, "Computer-aided ultrasonic testing of nonoxide ceramics," NDT International, 19(6), 1986

18. S. J. Klima, "NDE of Advanced Ceramics," Materials Evaluation, 44(5), 1986.

19. D. P. Stinton, A. J. Caputo, and R. A. Lowden, "Synthesis of Fiber-Reinforced SiC Composites by Chemical Vapor Infiltration," Ceramic Bulletin, 65(2), 1986.

20. P. J. Lamicq, G. A. Bernhart, M. M. Duchier, and J. G. Mace, "SiC/SiC Composite Ceramics," American Ceramic Society Bulletin, 65(2), 1986.

21. A. J. Caputo, D. P. Stinton, R. A. Lowden, and T. M. Bessmann, "FiberReinforced SiC Composites with Improved Mechanical Properties," American Ceramic Society Bulliten, 66(2), 1987.

22. D. P. Stinton, private communication.

23. J. A. Cornie, Y-M. Chaing, D. R. Uhlmann, A. Mortensen, J. M. Collins, "Processing of Metal and Ceramic Matrix Composites," Ceramic Bulletin, 65(2), 1986.

24. J. B. Walter, L. A. Lott, and P. M. Gammell, "Ultrasonic Characterization of Porosity in Advanced SiC Ceramic Composites," draft manuscript.

25. R. A. J. Sambell, D. H. Bowen, and D. C. Phillips, "Carbon fibre composites with ceramic and glass matrices," Journal of Material Science, 7, 1972.

26. D. B. Marshall and A. G. Evans, "Failure Mechanisms in CeramicFiber/Ceramic-Matrix Composites," Journal of the American Ceramic Society, 68(5), 1985.

27. M. J. Slavin and J. J. Gruber, "Ultrasonic Characterization of Ceramics," ASME Publication No. 87-GT-1.

28. K. Prewo and J. Brennan, "High-strength silicon carbide fibre-reinforced glassmatrix composites," Journal of Materials Science, 15, 1980.

29. T-I. Mah, M. G. Mendiratta, A. P. Katz, and K. S. Mazdiyasni, "Recent Developments in Fiber-Reinforced High Temperature Ceramic Composites," Ceramic Bulletin, 66(2), 1987.

30. T-I. Mah, M. G. Mendiratta, A. P. Katz, R. Ruh, and K. S. Mazdiyasni, "RoomTemperature Mechanical Behavior of Fiber-Reinforced Ceramic-Matrix Composites," Journal of the American Ceramic Society, 68(1), 1985.

31. R. A. J. Sambell, A. Briggs, D. C. Phillips, and D. H. Bowen, "Carbon fibre composites with ceramic and glass matrices," Journal of Material Science, 7, pp. 676-681, 1972.

32. R. W. Davidge, "Fibre-reinforced ceramics," Composites, 18(2), 1987.

33. C. L. Friant, G. B. Groff, D. C. Nagle, B. E. Buddemeyer, and S. L. Van Doren, "Ultrasonic Characterization of SiC Fiber-Reinforced Glass Matrix Composites", soon to be published.

34. G. Baaklini, "NDE Reliability and Process Control for Structural Ceramics," ASME Publication No. 87-GT-8.

35. A. Sarrafzadeh-Khoee and J. C. Duke, Jr., "Noncontacting Detection in Ultrasonic NDE of Materials: Simple Optical Sensor and Fiber Optics Interferometric Application," Review of Scientific Instruments, 57, p. 2321, 1986.

36. A. Sarrafzadeh-Khoee and J. C. Duke, Jr., "Small In-plane/Out-of-Plane Ultrasonic Displacement Measurement using Laser Speckle Interferometry," Experimental Techniques, 10(10), pp. 18-21, 1986.

37. R. D. Mindlin and R. K. Kaul, "Vibration of an Infinite Monoclinic Crystal Plate at High Frequencies and Long Wavelengths," Journal of the Acoust. Soc. of America, 34, pp. 1895-1901, 1962. 


\section{APPENDIX}

The basic plate wave problem may be formulated by considering the geometry diagrammed.

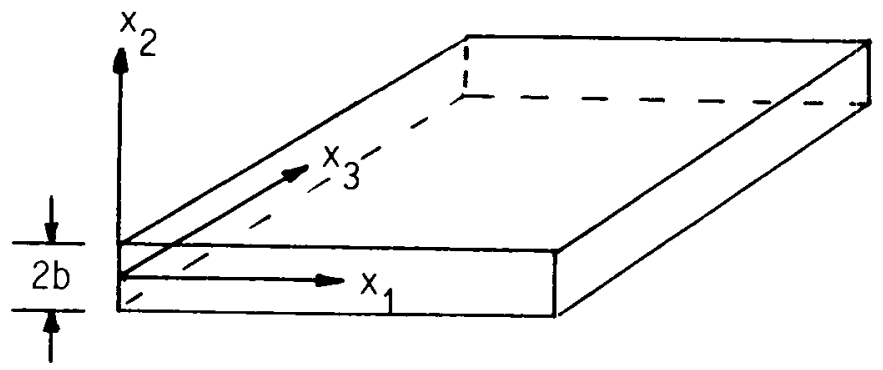

The first analyses were for long wavelength disturbances in thin, isotropic, homogeneous plates:

Flexural (Germain-Lagrange)

A1 $D \nabla^{2} \nabla^{2} \mathrm{u}_{2}+2 \rho \mathrm{bu} \ddot{\mathrm{u}}_{2}=0$ where $\mathrm{D}=4 \mu \mathrm{b}^{3} / 3(1-\nu)$

Extensional (Poisson)$$
\left(\lambda^{\prime}+\mu\right)\left(u_{1,1}+u_{3,3}\right)_{11}+\mu \nabla^{2} u_{1}=\rho \ddot{u}_{1}
$$

$$
\left(\lambda^{\prime}+\mu\right)\left(\mathrm{u}_{1,1}+\mathrm{u}_{3,3}\right), 3+\mu \nabla^{2} \mathrm{u}_{3}=\rho \ddot{u}_{3} \quad \lambda^{\prime}=2 \lambda \mu /(\lambda+\mu)
$$

For these equations $u_{i}=u_{i}\left(x_{1}, x_{3}, t\right)$.

For short wavelengths, typical of the $\mathrm{AU}$ method the thin plate theory is insufficient since the $u_{i}$ 's depend on the thickness, therefore variations across the thickness can not be ignored, ie. $u_{i}=u_{i}\left(x_{1}, x_{2}, x_{3}, t\right)$.

A4 $\quad(\lambda+\mu) \mathrm{u}_{\mathrm{k}, \mathrm{ik}}+\mu \mathrm{u}_{\mathrm{i}, \mathrm{kk}}=\rho \ddot{\mathrm{u}}_{\mathrm{i}}$

where

A5 $\sigma_{i j}=\lambda \delta_{i j} u_{k, k}+\mu\left(u_{i, j}+u_{j, i}\right)$ 
A4 can be separated into two uncoupled systems of equations using:

A6

$$
u_{i}+\phi_{i}+\epsilon_{i j k} \mathrm{H}_{k, j} \quad \mathrm{H}_{i, i}=0
$$

A7 $\quad \mathrm{v}_{\mathrm{p}}^{2} \nabla^{2} \phi=\phi$

$$
\mathrm{v}_{\mathrm{p}}^{2}=(\lambda+2 \mu) / \rho
$$

A8

$$
\mathrm{v}_{\mathrm{s}}{ }^{2} \nabla^{2} \mathrm{H}_{\mathrm{i}}=\mathrm{H}_{\mathrm{i}}
$$$$
\mathrm{v}_{\mathrm{s}}^{2}=\mu / \rho
$$

The conditions imposed by the boundaries may be described as:

$$
\sigma_{2 j}\left(x_{1}, \pm b, x_{3}, t\right)=0
$$

One possible solution for the case of SH waves finds $\mathrm{u}_{1}=\mathrm{u}_{2}=0$ and $\mathrm{u}_{3}=\mathrm{E}_{1} \operatorname{expi}\left(\xi \mathrm{x}_{1}+\beta \mathrm{x}_{2}-\omega t\right)+\mathrm{E}_{2} \operatorname{expi}\left(\xi \mathrm{x}_{1}-\beta \mathrm{x}_{2}-\omega t\right)$.

Another that is of more interest occurs if $\mathrm{H}_{1}=\mathrm{H}_{2}=0$ in eqn. A6.

$$
\begin{aligned}
& \text { A10 } \phi=\phi_{0} \operatorname{expi}\left(2 \xi \mathrm{x}_{\mathrm{i}} \pm \alpha \mathrm{x}_{2}-\omega t\right) \quad \omega^{2}=\mathrm{v}_{\mathrm{p}}{ }^{2}\left(\alpha^{2}+\xi^{2}\right) \\
& \text { All } \mathrm{H}_{3}=\mathrm{H}_{\mathrm{O}} \operatorname{expi}\left(\xi_{1} \pm \beta \mathrm{x}_{2}-\omega \mathrm{t}\right) \quad \omega^{2}=\mathrm{v}_{\mathrm{S}}^{2}\left(\beta^{2}+\xi^{2}\right) \\
& \text { A12 } \theta_{1}= \pm \tan ^{-1}(\xi / \alpha) \quad P \text { wave } \\
& \text { A13 } \theta_{2}= \pm \tan ^{-1}(\xi / \beta) \quad \text { SV wave }
\end{aligned}
$$

A harmonic wave motion in the $\mathrm{x}_{1}$ - direction with phase velocity $\mathrm{v}=\omega / \xi$ and wavelength $\lambda=2 \pi / \xi$ may be seen to be a superposition, with the appropriate choice of phase angles and amplitudes, of four waves of the type described in eqn A10 and four waves of the type described in eqn A11; specifically:

$$
\begin{array}{ll}
A 14 & \phi=\left(A \sin \alpha x_{2}+B \cos \alpha x_{2}\right) \exp i\left(\xi x_{1}-\omega t\right) \\
A 15 & H_{3}=i\left(C \sin \beta x_{2}+D \cos \beta x_{2}\right) \operatorname{expi}\left(\xi x_{1}-\omega t\right)
\end{array}
$$

The general form of the displacements and stresses associated with these waves could be written:

$$
\begin{array}{ll}
\text { Al6 } & u_{i}=U_{i} \operatorname{expi}\left(\xi x_{1}-\omega t\right) \\
\text { A17 } & \sigma_{i j}=T_{i j} \operatorname{expi}\left(\xi x_{1}-\omega t\right)
\end{array}
$$


Now this type of wave motion may be divided into two distinct types:

1) symmetric motion about the $x_{1}-x_{3}$ plane
A18 $\mathrm{U}_{1}=\mathrm{i}\left(\mathrm{E} \xi \cos \alpha \mathrm{x}_{2}+\mathrm{C} \beta \cos \beta \mathrm{x}_{2}\right)$
A19 $\mathrm{U}_{2}=\left(-\mathrm{E} \alpha \sin \alpha \mathrm{x}_{2}+\mathrm{C} \xi \sin \beta \mathrm{x}_{2}\right)$
A20 $\mathrm{T}_{22}=\mu\left[\mathrm{E}\left(\xi^{2}-\beta^{2}\right) \cos \alpha \mathrm{X}_{2}+2 \mathrm{C} \xi \beta \cos \beta \mathrm{X}_{2}\right]$
A21 $\mathrm{T}_{21}=\mathrm{i} \mu\left[-2 \mathrm{~B} \xi \alpha \sin \alpha \mathrm{x}_{2}+\mathrm{C}\left(\xi^{2}-\beta^{2}\right) \sin \beta \mathrm{x}_{2}\right]$
A22 $\mathrm{T}_{11}=\mu\left[\mathrm{E}\left(2 \alpha^{2}-\beta^{2}-\xi^{2}\right) \cos \alpha \mathrm{X}_{2}-2 \mathrm{C} \xi \beta \cos \beta \mathrm{X}_{2}\right]$
A23 $F_{1}(\alpha, \beta, \xi)=\left(\xi^{2}-\beta^{2}\right)^{2} \cos \alpha \mathrm{b} \sin \beta \mathrm{b}+4 \alpha \beta \xi^{2} \sin \alpha \mathrm{b} \cos \beta \mathrm{b}=0$

2) antisymmetric motion about the $x_{1}-x_{3}$ plane

$$
\begin{array}{ll}
\text { A24 } & \mathrm{U}_{1}=i\left(A \xi \sin \alpha \mathrm{x}_{2}-\mathrm{D} \beta \sin \beta \mathrm{x}_{2}\right) \\
\mathrm{A} 25 & \mathrm{U}_{2}=\left(\mathrm{A} \alpha \cos \alpha \mathrm{x}_{2}+\mathrm{D} \xi \cos \beta \mathrm{x}_{2}\right) \\
\mathrm{A} 26 & \mathrm{~T}_{22}=\mu\left[\mathrm{A}\left(\xi^{2}-\beta^{2}\right) \sin \alpha \mathrm{x}_{2}-2 \mathrm{D} \xi \beta \sin \beta \mathrm{x}_{2}\right] \\
\mathrm{A} 27 & \mathrm{~T}_{21}=\mathrm{i} \mu\left[2 \mathrm{~A} \alpha \xi \cos \alpha \mathrm{x}_{2}+\mathrm{D}\left(\xi^{2}-\beta^{2}\right) \cos \beta \mathrm{x}_{2}\right] \\
\mathrm{A} 28 & \mathrm{~T}_{11}=\mu\left[\mathrm{A}\left(2 \alpha^{2}-\beta^{2}-\xi^{2}\right) \sin \alpha \mathrm{x}_{2}+2 \mathrm{D} \xi \beta \sin \beta \mathrm{x}_{2}\right] \\
\mathrm{A} 29 & \mathrm{~F}_{2}(\alpha, \beta, \xi)=\left(\xi^{2}-\beta^{2}\right)^{2} \sin \alpha \mathrm{b} \cos \beta \mathrm{b}+4 \alpha \beta \xi^{2} \sin \beta \mathrm{b} \cos \alpha \mathrm{b}=0
\end{array}
$$

The two frequencies eqns, can be written in reduced form and combined phase velocity calculations to yield the following dispersion relations:

A30 $F(\alpha, \beta, \xi) \equiv \tan \beta \mathrm{b} / \tan \alpha \mathrm{b}+\left[\frac{4 \alpha \beta \xi^{2}}{\left(\xi^{2}-\beta^{2}\right)^{2}}\right]^{ \pm 1}=0$

+1 symmetric, -1 antisymmetric
A31 $\alpha^{2}=\left(\omega^{2} / \mathrm{v}_{\mathrm{p}}{ }^{2}-\xi^{2}\right)$
A32 $\beta^{2}=\left(\omega^{2} / \mathrm{v}_{\mathrm{s}}^{2}-\xi^{2}\right)$ 


\section{Extension to Anisotropic Material}

For the general anisotropic case, the following homogeneous system of equations can be derived by equilibrium considerations:

A33 $A_{k}\left(C^{\prime}{ }^{\prime j k l} \xi^{\prime} \xi^{\prime} l^{\prime}-\Omega^{2} \delta_{i k}\right)=0$

where

$\mathrm{C}^{\prime}{ }_{\mathrm{ijkl}}=\mathrm{C}_{\mathrm{ijkl}} / \mathrm{C}_{1212}$ dimensionless stiffness matrix terms

$\xi^{\prime} \mathrm{i}=2 \mathrm{~b} \xi_{\mathrm{i}} / \pi$ dimensionless wave number

$\Omega=\omega / \omega_{\mathrm{s}}$ dimensionless frequency

and

$\omega_{\mathrm{S}}=(\pi / 2 \mathrm{~b})\left(\mathrm{C}_{1212} / \rho\right)^{1 / 2}$ resonant frequency of shear wave,

$\mathbf{A}_{k}$ is the amplitude of the particle displacement.

For a given direction $\xi_{i} /|\xi|$, the above expression yields three distinct roots, corresponding to three different wave speeds and particle displacement directions. It is also necessary to include stress free conditions at the upper and lower surfaces. Since the three waves are coupled, the situation is more complicated than the isotropic case. The anisotropic constitutive expression is significantly more cumbersome making the transcendental equations more awkward to handle.

The approach being followed in pursuing this analysis is as follows:

1 Define a direction of propagation that is of interest $\xi_{1}: \xi_{3}$

2 Formulate the equations of equilibrium

3 Describe the displacements, assuming standing waves in the $x_{2}$-direction with three amplitude ratios for each wave number $\xi^{\prime} 2^{(n)}$ (where $n$ has 3 values corresponding to each solution of equation A33). 
4 Write the stresses in terms of particle displacements, using the constitutive relations and then impose the stress free boundary condition; this results in a set of 6 homogeneous equations.

$5 \mathrm{~A}$ unique solution is available if the determinant of the coefficients is equal to zero.

This result along with the equations of equilibrium provides the dispersion relations for the Lamb wave propagation for a fully anisotropic plate. This case has not been fully solved due to the complicated nature of the equations and the lack of a practical example. Special cases, such as the case of the monoclinic crystal, have been solved and detailed descriptions are available.

The primary difference that may be expected is the existence of extra shear modes. Also as has been suggested by Mindlin and Kaul, 37 the frequency of one simple thickness mode may coincide with that of another leading to difficulties in deriving the dispersion curves. Nevertheless work is continuing on the orthotropic symmetry case and in particular the details of the transverse resonance induced wave propagation. 


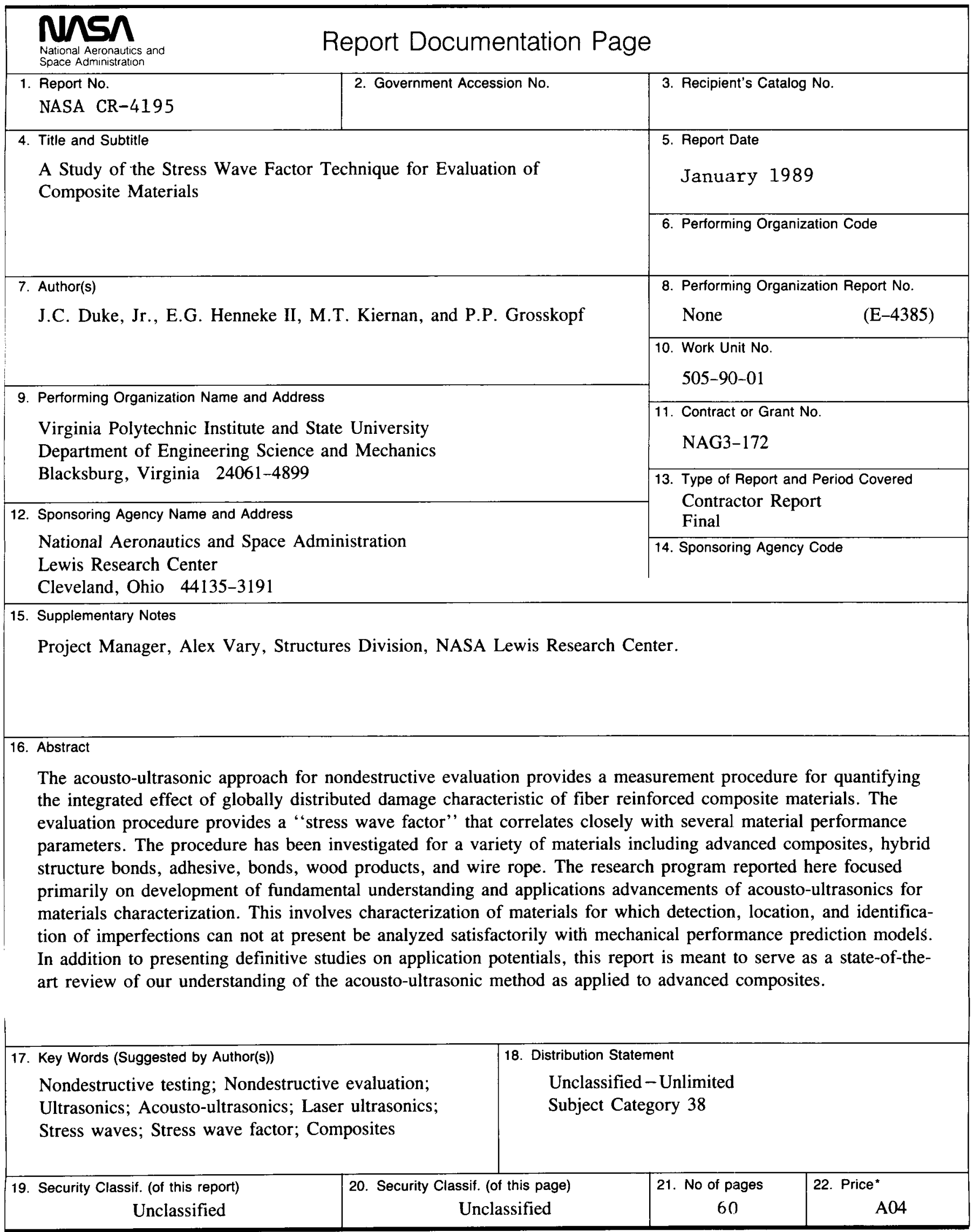

NASA FORM 1626 OCT $86 \quad$ *For sale by the National Technical Information Service, Springfield, Virginia 22161 